\author{
UNIVERSIDADE DE SÃO PAULO \\ FACULDADE DE CIÊNCIAS FARMACÊUTICAS \\ Programa de Pós-Graduação em Fármaco e Medicamentos \\ Área de Produção e Controle Farmacêuticos
}

Identificação rápida de contaminantes microbianos em

produtos farmacêuticos

Natália Monte Rubio de Brito

MESTRADO

Orientador: Prof. Felipe Rebello Lourenço

São Paulo - 2019 



\section{UNIVERSIDADE DE SÃO PAULO \\ FACULDADE DE CIÊNCIAS FARMACÊUTICAS \\ Programa de Pós-Graduação em Fármaco e Medicamentos \\ Área de Produção e Controle Farmacêuticos}

Identificação rápida de contaminantes microbianos em produtos farmacêuticos

Natália Monte Rubio de Brito

Versão Original

Dissertação para obtenção do Título de Mestre

Orientador: Prof. Dr. Felipe Rebello Lourenço

São Paulo - 2019 
Ficha Catalográfica elaborada eletronicamente pelo autor, utilizando o programa desenvolvido pela Seção Técnica de Informática do ICMC/USP e adaptado para a Divisāo de Biblioteca e Documentação do Conjunto das Químicas da USP

Bibliotecária responsável pela orientação de catalogação da publicação: Marlene Aparecida Vieira - CRB - 8/5562

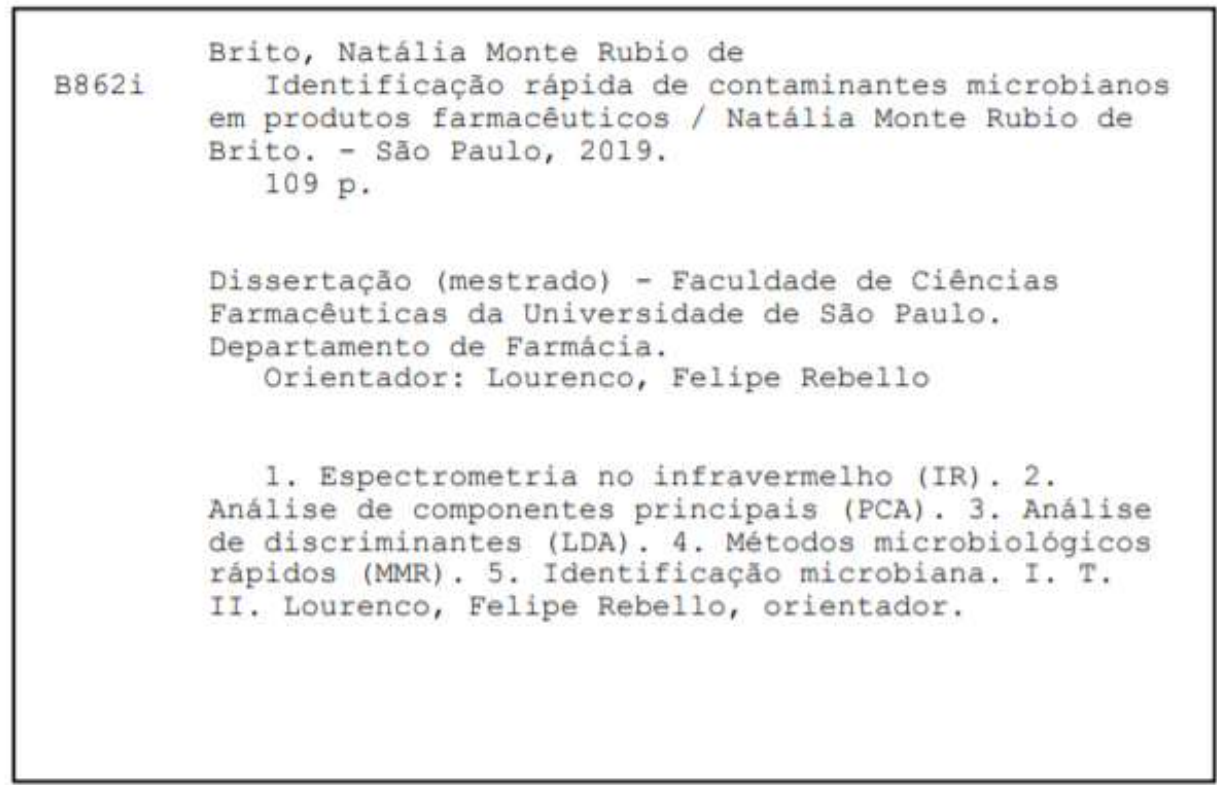




\title{
Identificação rápida de contaminantes microbianos em produtos farmacêuticos
}

\author{
Comissão Julgadorada
}

Dissertação para obtenção do Título de Mestre

Prof. Dr. Felipe Rebello Lourenço

orientador/presidente

1o. examinador

$2^{\circ}$. Examinador

$3^{\circ}$. Examinador

São Paulo, de de 



\section{DEDICATÓRIA}

Dedico esse trabalho aos meus pais, pelo o apoio, paciência e por acreditarem em realizar este sonho. 



\section{AGRADECIMENTOS}

Primeiramente, agradeço a Deus.

Agradeço, ao meu orientador Prof. Felipe Rebello Lourenço, por todo o aprendizado, paciência e companheirismo.

Aos meus pais e a minha família por todo o apoio nesta etapa acadêmica.

Agradeço, a equipe do Laboratório de Planejamento e Síntese de Quimioterápitocs contra Doenças Negligenciadas (LAPEN), em especial o Charles de Lima Brito por me auxiliar com o equipamento.

Aos participantes Comissão examinadora do Exame de Qualificação Adriana Bugno e Marina de Souza Braga, pelas suas sugestões e orientações.

Aos professores da Faculdade Ciências Farmacêuticas (FCF-USP) e ao Programa de Pós-Graduação. 



\section{RESUMO}

BRITO, N.M.R. Identificação rápida de contaminantes microbianos em produtos farmacêuticos. 2019. 109p. Dissertação para obtenção do Título de MestreDepartamento de Farmácia, Faculdade de Ciências Farmacêuticas, Universidade de São Paulo, São Paulo.

A qualidade microbiológica de medicamentos é fundamental para garantir sua eficácia e segurança. Os métodos convencionais para identificação microbiana em produtos não estéreis são amplamente utilizados, entretanto são demorados e trabalhosos. O objetivo deste trabalho é desenvolver método microbiológico rápido (MMR) para a identificação de contaminantes em produtos farmacêuticos utilizando a espectrofotometria de infravermelho com transformada de Fourier com reflectância total atenuada (FTIR-ATR). Análise de componentes principais (PCA) e análise de discriminantes (LDA) foram utilizadas para obter um modelo de predição com a capacidade de diferenciar o crescimento de oriundo de contaminação por Bacillus subtilis (ATCC 6633), Candida albicans (ATCC 10231), Enterococcus faecium (ATCC 8459), Escherichia coli (ATCC 8739), Micrococcus luteus (ATCC 10240), Pseudomonas aeruginosa (ATCC 9027), Salmonella Typhimurium (ATCC 14028), Staphylococcus aureus (ATCC 6538) e Staphylococcus epidermidis (ATCC 12228). Os espectros de FTIR-ATR forneceram informações quanto à composição de proteínas, DNA/RNA, lipídeos e carboidratos provenientes do crescimento microbiano. As identificações microbianas fornecidas pelo modelo PCA/LDA baseado no método FTIR-ATR foram compatíveis com aquelas obtidas pelos métodos microbiológicos convencionais. O método de identificação microbiana rápida por FTIR-ATR foi validado quanto à sensibilidade (93,5\%), especificidade $(83,3 \%)$ e limite de detecção (17-23 UFC/mL de amostra). Portanto, o MMR proposto neste trabalho pode ser usado para fornecer uma identificação rápida de contaminantes microbianos em produtos farmacêuticos.

PALAVRAS-CHAVE: Espectrometria no infravermelho (IR); análise de componentes principais (PCA); análise de discriminantes (LDA); métodos microbiológicos rápidos (MMR); identificação microbiana. 



\begin{abstract}
BRITO, N.M.R. Rapid identification of microbial contaminants in pharmaceutical products. 2019. 109p. Dissertation for Master degree - Department of Pharmacy, School of Pharmaceutical Sciences, University of São Paulo, São Paulo.
\end{abstract}

Microbiological quality of pharmaceuticals is fundamental in ensuring efficacy and safety of medicines. Conventional methods for microbial identification in non-sterile drugs are widely used, however are time-consuming and laborious. The aim of this paper was to develop a rapid microbiological method (RMM) for identification of contaminants in pharmaceutical products using Fourier transform infrared with attenuated total reflectance spectrometry (FTIR-ATR). Principal components analysis (PCA) and linear discriminant analysis (LDA) were used to obtain a predictive model with capable to distinguish Bacillus subtilis (ATCC 6633), Candida albicans (ATCC 10231), Enterococcus faecium (ATCC 8459), Escherichia coli (ATCC 8739), Micrococcus luteus (ATCC 10240), Pseudomonas aeruginosa (ATCC 9027), Salmonella Typhimurium (ATCC 14028), Staphylococcus aureus (ATCC 6538), and Staphylococcus epidermidis (ATCC 12228) microbial growth. FTIR-ATR spectra provide information of protein, DNA/RNA, lipids, and carbohydrates constitution of microbial growth. Microbial identification provided by PCA/LDA based on FTIR-ATR method were compatible to those obtained using conventional microbiological methods. FTIR-ATR method for rapid identification of microbial contaminants in pharmaceutical products was validated by assessing the sensitivity (93.5\%), specificity (83.3\%), and limit of detection (17-23 $\mathrm{CFU} / \mathrm{mL}$ of sample). Therefore, the RMM proposed in this work may be used to provide a rapid identification of microbial contaminants in pharmaceutical products.

KEYWORDS: Infrared spectrometry (IR); principal components analysis (PCA); linear discriminant analysis (LDA); rapid microbiological methods (RMM); microbial identification. 



\section{SUMÁRIO}

1. INTRODUÇÃ

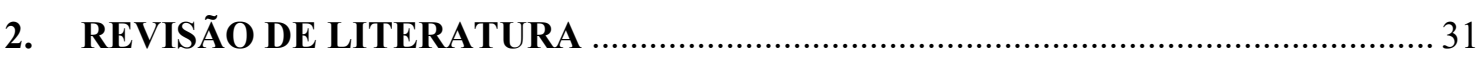

2.1. Qualidade Microbiológica de Produtos Farmacêuticos......................................... 31

2.2. Problemas decorrentes da contaminação microbiana de medicamentos .............. 32

2.3. Fontes de contaminação microbiana de medicamentos ............................................... 34

2.4. Fatores que afetam contaminação microbiana de medicamentos .......................... 36

2.5. Conservação microbiológica de medicamentos .............................................................38

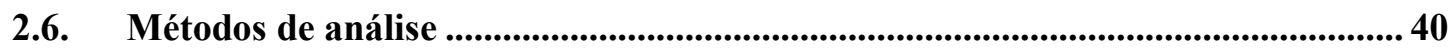

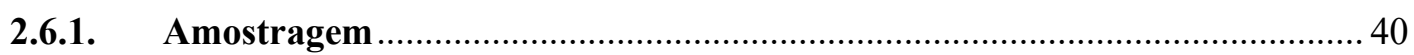

2.6.2. Contagem de microrganismos viáveis presente no produto .......................... 41

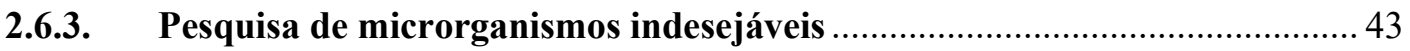

2.7. Microrganismos usualmente pesquisados em medicamentos.................................... 45

2.7.1. Microrganismos do gênero Enterobacteriacea …............................................. 45

2.7.2. Microrganismos do gênero Pseudomonas ....................................................... 47

2.7.3. Microrganismos do gênero Staphylococcus..................................................... 48

2.8. Etapas envolvidas na pesquisa de microrganismos patogênicos............................49

2.8.1. Etapa de enriquecimento da cultura microbiana em meio não seletivo ....... 50

2.8.2. Etapa de identificação utilizando meio de cultura seletivo.............................51

2.9. Adequação dos métodos de contagem de microrganismos viáveis e de pesquisa de microrganismos indesejáveis .......................................................................................................5 53

2.10. Métodos microbiológicos alternativos ........................................................................5

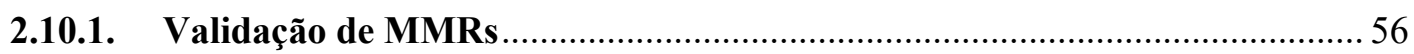

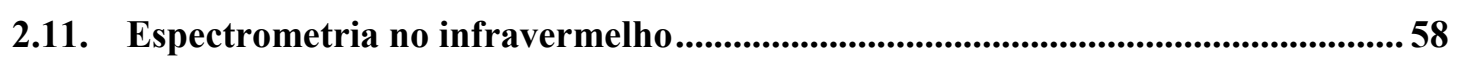

2.12. Ferramentas estatísticas usualmente empregadas em quimiometria ....................59

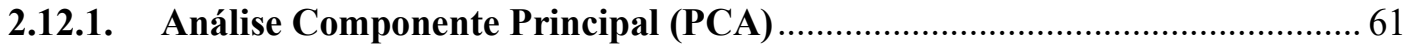

2.12.2. Análise Discriminante Linear (LDA) .......................................................... 61

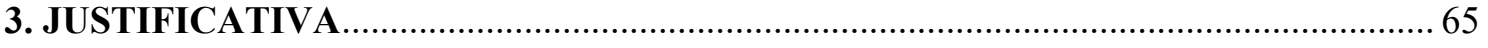

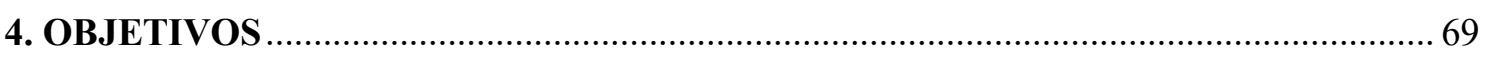

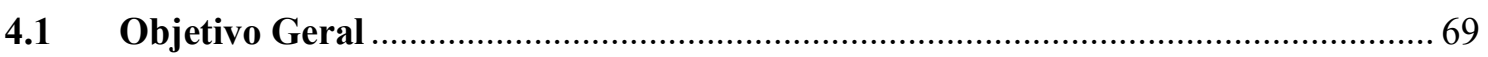

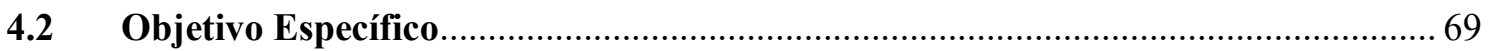

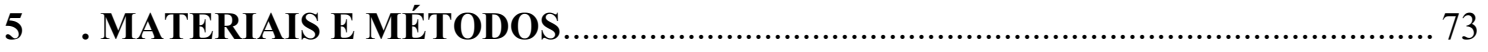

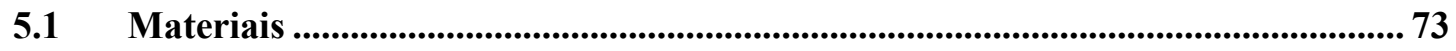

5.1.1 Meios de cultura ................................................................................................................. 73

5.1.2 Microrganismos......................................................................................................... 74

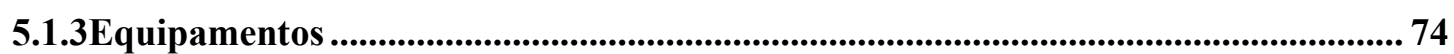




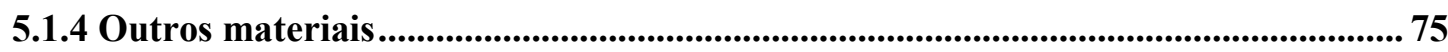

5.2 Preparação e pré-incubação das amostras de produtos farmacêuticos................... 75

5.3 Métodos microbiológicos convencionais para a identificação microbiana............. 76

5.4 Espectrometria no infravermelho com transformada de Fourier com reflectância total atenuada (FTIR-ATR) ................................................................................................... 78

5.5 Análise dos dados ..................................................................................................... 79

5.6 Validação do método FTIR-ATR para identificação microbiana rápida .............. 80

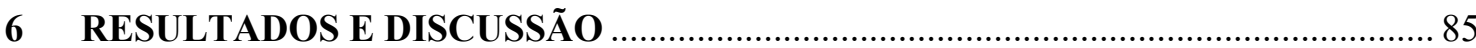

6.1 Análise por FTIR-ATR do crescimento microbiano ................................................... 85

6.2 Exploração dos dados utilizando análise de componentes principais (PCA)....... 87

6.3 Classificação dos dados utilizando análise de discriminantes linear (LDA) ......... 90

6.4 Validação do método FTIR-ATR para identificação microbiana rápida .............. 92

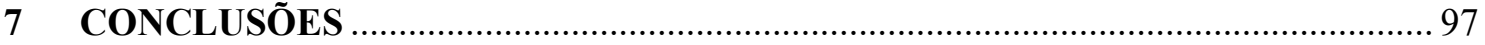

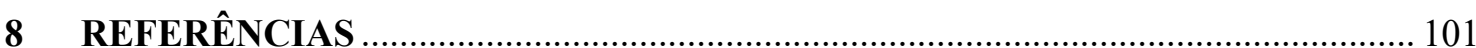




\section{LISTA DE TABELAS}

Tabela 1 Atribuição das bandas frequentemente encontradas nos espectros IR

microbianos

Tabela 2 Respostas de crescimento esperados de Bacillus subtilis (ATCC 6633), Candida albicans (ATCC 10231), Enterococcus faecium (ATCC 8459), Escherichia coli (ATCC 8739), Micrococcus luteus (ATCC 10240), Pseudomonas aeruginosa (ATCC 9027), Salmonella Typhimurium (ATCC 14028), Staphylococcus aureus (ATCC 6538) e Staphylococcus epidermidis (ATCC 12228) nos meios ágar MacConkey, ágar Cetrimida e ágar sal de manitol.......

Tabela 3 Resultados da análise de componentes principais (PCA) obtidos a partir dos espectros FTIR-ATR na região de 800 a $2000 \mathrm{~cm}-1$ (primeira derivada suavizada) dos crescimentos de Bacillus subtilis (ATCC 6633), Candida albicans (ATCC 10231), Enterococcus faecium (ATCC 8459), Escherichia coli (ATCC 8739), Micrococcus luteus (ATCC 10240), Pseudomonas aeruginosa (ATCC 9027), Sal7monella Typhimurium (ATCC 14028), Staphylococcus aureus (ATCC 6538) e Staphylococcus epidermidis (ATCC 12228).

Tabela 4 Matriz de confusão obtida com o modelo LDA a partir dos espectros de FTIR-ATR na região entre 800 e 2000 cm-1 (primeira derivada suavizada) com 4 PCs preditores

Tabela 5 Tabela de contingência para presença/ausência de crescimento microbiano e identificação microbiana rápida de contaminantes em produtos farmacêuticos pelo método FTIR-ATR 



\section{LISTA DE FIGURAS}

Figura 1 Espectrofotômetro infravermelho com transformada de Fourier (FTIR) (esquerda) e aparato de reflectância total atenuada (ATR) (direita) utilizados nas determinações dos espectros das biomassas na região entre 4.000 e $550 \mathrm{~cm}^{-1}$

Figura2 Esquema de diluições decimais para a realização do ensaio de limite de detecção.

Figura3 Espectros na região de 800 a $2000 \mathrm{~cm}^{-1}$ (primeira derivada suavizada) obtidos dos crescimentos de Bacillus subtilis (ATCC 6633), Candida albicans (ATCC 10231), Enterococcus faecium (ATCC 8459), Escherichia coli (ATCC 8739), Micrococcus luteus (ATCC 10240), Pseudomonas aeruginosa (ATCC 9027), Salmonella Typhimurium (ATCC 14028), Staphylococcus aureus (ATCC 6538) e Staphylococcus epidermidis (ATCC 12228).

Figura4 Gráfico de dispersão 3D dos scores para os 3 primeiros componentes principais (PC1, PC2 e PC3) para os espectros obtidos a partir do crescimento de Bacillussubtilis (ATCC 6633), Candida albicans (ATCC 10231), Enterococcus faecium (ATCC 8459), Escherichia coli (ATCC 8739), Micrococcus luteus (ATCC 10240), Pseudomonas aeruginosa (ATCC 9027), Salmonella Typhimurium (ATCC 14028), Staphylococcus aureus (ATCC 6538) e Staphylococcus epidermidis (ATCC 12228). 



\section{LISTA SIGLAS / ABREVIATURAS}

ANVISA......... Agência Nacional de Vigilância Sanitária

ATCC.......... American Type Culture Collection

ATR............... Reflectância Total Atenuada, do inglês Attenued Total Reflectance

EIEC............. E. coli enteroinvasoras

EPEC........... E.coli enteropatogênicas

FTIR.............. Espectrometria no infravermelho com transformada de Fourier, do inglês Fourier Transfored Infrared Spectrometry

LDA............... Análise Linear de Discriminantes, do inglês Linear Discriminant Analysis

MMR............. Método Microbiológico Rápido

NMP ............. Número mais provável

PCA.............. Análise de Componentes Principais, do inglês Principal Component Analysis

SDA.............. Sabouraud dextrose ágar

SDB............... Caldo Sabouraud dextrose

TSA.............. Ágar triptona soja

TSB............. Caldo triptona soja

UFC............. Unidade formada colônia

XLD............. Xilose-Lisina-Desoxicolato 

INTRODUÇÃO 



\section{INTRODUÇÃO}

As exigências de qualidade microbiológica dos produtos farmacêuticos são diferentes de acordo com suas vias de administração. Produtos injetáveis e oftálmicos têm exigência de esterilidade. Por outro lado, os produtos orais e tópicos são referidos como produtos não estéreis. Em outras palavras, admite-se a existência de um nível de contaminação, desde que não haja impacto em sua qualidade, segurança e eficácia(Denyer \& Baird, 2007)(Pinto, et al., 2015).

No que diz respeito à qualidade microbiológica, devem ser identificadas as fontes de contaminação direta e indireta, tais como matérias-primas, água, equipamento, materiais de embalagem, ambiente e operadores. $\mathrm{O}$ armazenamento, a distribuição/transporte e o uso final pelo paciente devem igualmente ser considerados (Denyer \& Baird, 2007)(Pinto, et al., 2015).

Características tais como a atividade da água elevada, $\mathrm{pH}$ perto da neutralidade e da presença dos excipientes que podem ser usados como fontes nutritivas favorecem o crescimento microbiano em produtos farmacêuticos. Por outro lado, os produtos farmacêuticos com baixa atividade de água, com presença de excipientes com atividade antimicrobiana ou submetidos a altas temperaturas durante o processo de fabricação, são menos susceptíveis à contaminação microbiana(United States Pharmacopeia, 2016).

A qualidade microbiológica dos produtos não estéreis abrange dois aspectos pertinentes: 1) a avaliação da carga microbiana (contagens microbianas) e 2) a ausência de microrganismos patogênicos (United States Pharmacopeia, 2016)(Agência Nacional de Vigilância Sanitária (ANVISA), 2010). A ausência de microrganismos patogênicos é necessária consoante à utilização (via de administração). Os produtos farmacêuticos para 
uso oral têm a exigência de ausência de microrganismos do gênero Salmonela e bactérias coliformes, tais como Escherichia coli. Por outro lado, os produtos tópicos requerem a ausência de Staphylococcus aureus e Pseudomonas aeruginosa(United States Pharmacopeia, 2016)(Agência Nacional de Vigilância Sanitária (ANVISA), 2010).

Os métodos de identificação microbiana geralmente utilizada para produtos farmacêuticos são os descritos em compêndios oficiais, como farmacopéia brasileira(Agência Nacional de Vigilância Sanitária (ANVISA), 2010)e farmacopéia americana (United States Pharmacopeia, 2016). Estes são métodos tradicionais que envolvem duas etapas: 1) enriquecimento da cultura microbiana em meios não seletivos; e 2) identificação usando meios de cultura para o crescimento seletivo e/ou testes bioquímicos. Normalmente, esses métodos são trabalhosos, uma vez que envolvem vários meios de cultura seletiva, e pode levar até semanas (Denyer \& Baird, 2007).

Os métodos microbiológicos rápidos (MMRs) têm sido desenvolvidos como alternativas aos métodos microbiológicos tradicionais para a análise quantitativa e qualitativa dos alimentos, cosméticos, medicamentos e amostras clínicas (Easter, 2003)(Pinto, et al., 2015). Apesar das vantagens dos métodos microbiológicos rápidos (MMRs), ainda existem algumas barreiras, principalmente devido a questões regulatórias. A validação do método é etapa crítica para a aprovação de MMRs por agências reguladoras. Além disso, a equivalência do MMR com o método tradicional deve ser demonstrada através de comparações estatísticas (United States Pharmacopeia, 2016).

O MMR deve ser escolhido levando-se em conta a finalidade do ensaio e a compatibilidade com o produto. Os métodos principais são: 1) métodos baseados no crescimento microbiano, como métodos eletroquímicos, métodos de bioluminescência, métodos baseados na detecção de produção de gás, e emprego de substratos cromogênico(Bugno, et al., 2015)(Ferreira, et al., 2014)(Parveen, et al., 2011)(Shah \& 
Naseby, 2015)(Verdonk, et al., 2010)(Lourenço, et al., 2015)(Bugno, et al., 2017); 2) métodos baseados na viabilidade, tais como citometria de fluxo e detecção de ATP (Taguri, et al., 2011)(Ugarova, et al., 2016); 3) métodos baseados na análise fenotípica, tais como técnicas imuno-fluorescência, espectrometria infravermelha (FTIR), espectroscopia de massa (MALDI-TOF), e análise de ácidos graxos perfil por cromatografia em fase gasosa (CG) (Davis \& Mauer, 2010)(Filip, et al., 2004)(Fischer, et al., 2006)(Helm \& Naumann, 1995)(Kuligowski, et al., 2012)(Liu, et al., 2016)(Pacheco \& Pinto, 2010)(Song, et al., 2016)(Tidwell, et al., 2015)(Tong, et al., 2010)(Wu, et al., 2013); e 4) métodos baseados na análise do genótipo, tais como técnicas do PCR e identificação da impressão digital (Kane, et al., 2009)(Maurischat, et al., 2015).

Considerando as limitações dos métodos tradicionais, o desenvolvimento de MMR para a identificação de contaminantes em produtos farmacêuticos é de interesse para a indústria farmacêutica. A espectrometria no infravermelho com transformada de Fourier com reflexão total atenuada (FTIR-ATR) tem vantagens, como o número reduzido de etapas envolvidas na identificação microbiana, resultados rápidos, e facilidade de automação e de rastreamento de dados(Davis \& Mauer, 2010)(Filip, et al., 2004)(Fischer, et al., 2006)(Helm \& Naumann, 1995)(Kuligowski, et al., 2012)(Tidwell, et al., 2015).

Portanto, o objetivo deste trabalho foi desenvolver e validar um método FTIRATR para identificação rápida de contaminantes em produtos farmacêuticos. Ferramentas de quimiometria, como a principal análise de componentes (PCA) e a análise de discriminante (LDA), foram utilizadas com o intuito de estabelecer um modelo capaz de distinguir e classificar os contaminantes em produtos farmacêuticos com assertividade. Assim, o método FTIR-ATR pode complementar (ou mesmo substituir) os métodos microbiológicos convencionais utilizados (United States Pharmacopeia, 2016). 
REVISÃO DE LITERATURA 



\section{REVISÃO DE LITERATURA}

\subsection{Qualidade Microbiológica de Produtos Farmacêuticos}

No início do século XX surgiu o conceito da qualidade dos produtos farmacêuticos, considerando desde o processo de fabricação, matérias-primas, materiais de embalagem, até o armazenamento, de forma a garantir a qualidade, segurança e eficácia dos medicamentos(Moretto \& Calixto, 2009).

No que diz respeito à qualidade microbiológica, devem ser identificadas as fontes de contaminação diretas e indiretas, tais como as matérias-primas, água, equipamentos, materiais de embalagem, ambiente e operador. Também deve ser considerado o armazenamento até a dispensação e uso final do medicamento pelo paciente (Amaral, 2016).

A qualidade microbiológica requerida dos produtos farmacêuticos pode ser diferente, conforme a sua via de administração. Os produtos farmacêuticos injetáveis e oftálmicos tem exigência de esterilidade. Porém, os produtos de uso oral e tópico são denominados produtos não estéreis, ou seja, é admitida a existência de um nível de contaminação, desde que não haja comprometimento da qualidade, segurança e eficácia do produto (Fung, 2002).

A qualidade microbiológica de produtos não estéreis abrange dois aspectos relevantes: 1) a avaliação da carga microbiana (contagem microbiana) e 2) a ausência de microrganismos patogênicos. Características tais como alta atividade de água, pH próximo a neutralidade e presença de excipientes que possam ser utilizados como fontes de nutriente favorecem o crescimento microbiano em produtos farmacêuticos. Por outro 
lado, produto com baixa atividade de água, com presença de excipientes com atividade antimicrobiana ou submetidos a altas temperaturas durante o processo de fabricação são menos susceptíveis a contaminação microbiana (Pinto, et al., 2014).

A ausência de microrganismos patogênicos é requerida em função do uso (via de administração) do medicamento. Produtos farmacêuticos de uso oral têm exigência de ausência de microrganismos do gênero Salmonella e coliformes, tais como a Escherichia coli. Por outro lado, produtos de uso tópico requerem a ausência de Staphylococcus aureus e Pseudomonas aeruginosa (Agência Nacional de Vigilância Sanitária (ANVISA), 2010)(United States Pharmacopeia, 2016).

Os métodos de identificação microbianos usualmente empregados para os produtos farmacêuticos são aqueles descritos nas principais farmacopéias brasileiras e farmacopeia americana. São métodos tradicionais que envolvem duas etapas: 1) etapa de enriquecimento da cultura microbiana em meio não seletivo e 2) etapa de identificação utilizando-se meios de cultura para crescimento seletivo e/ou testes bioquímicos. No geral, estes métodos são trabalhosos (pois envolvem diversas etapas de crescimento seletivo) e demorados (podendo levar até semanas).

\subsection{Problemas decorrentes da contaminação microbiana de medicamentos}

A contaminação microbiana em produtos farmacêuticos pode resultar em problemas quanto ao risco de infecções em decorrência de seu uso, assim a deterioração microbiana do produto, com possível perda de eficácia e segurança(Pinto, et al., 2015). 
Os mesmos produtos que não apresentem alterações sensoriais evidentes, podem oferecer risco de infecção, dependendo de fatores como o tipo e quantidade de microrganismo presente, a via de administração e a resistência do paciente.

Microrganismos patogênicos constituem-se na maior preocupação no que diz respeito à possibilidade de infecções decorrente do uso de produtos contaminados. Entretanto, mesmo microrganismos não patogênicos oferecem risco de infecções oportunistas, particularmente se estiveram acima da carga microbiana efetiva (quantidade mínima de microrganismo capaz de causar infecção)

O risco de infecção também está associado ao uso pretendido do produto. Considerando-se a via de administração, quanto mais invasiva maior o risco de infecção. Neste sentido, a contaminação de produtos injetáveis e oftálmicos constitui importante aspecto de preocupação. Produtos de uso oral ou tópico (em pele intacta) apresentam menor risco de infecção quando comparado àqueles aplicados em pele lesionadas ou mucosas. A hemodiálise representa problema particular, em decorrência do alto risco de septicemia associada o fluido da diálise contaminado(Mota, 2017).

Outro aspecto que impacta no risco de infecções decorrentes do uso de produtos com contaminação microbiana diz respeito à resistência do paciente. Geralmente, crianças e idosos apresentam maior risco em relação aos adultos. Paciente que apresentem doenças autoimunes, AIDS, leucemias, dentre outras, também estão mais susceptíveis a infecções em decorrência do uso de produtos com contaminação microbiana.

Adicionalmente, há de se considerar que a contaminação microbiana pode resultar de deterioração do produto. A capacidade do microrganismo contaminante em promover a deterioração depende de sua capacidade em produzir enzimas degradativas (por exemplo, proteases e peptidases). Neste sentido, constituição do produto também deve ser considerada. A degradação de componentes da formulação pode levar a alterações 
sensoriais quanto a cor, odor e sabor, além de alterações de $\mathrm{pH}$, separação de fases, degradação do princípio ativo e redução da biodisponibilidade. Em outras palavras, a deterioração microbiana compromete a qualidade, segurança e eficácia do produto(Mota, 2017)(Pinto, et al., 2015)

\subsection{Fontes de contaminação microbiana de medicamentos}

No que diz respeito à qualidade microbiológica, devem ser identificadas as fontes de contaminação direta, tais como matérias-primas, água, materiais de embalagem; e indireta, como os equipamentos, ambiente e operadores (Denyer \& Baird, 2007).

A qualidade microbiana do produto final pode depender amplamente da qualidade das matérias-primas (fármacos e excipientes). Geralmente, as matérias-primas de origem sintética (por exemplo, a maioria dos fármacos) oferecem menor risco de contaminação microbiana quando comparadas as de origem natural (por exemplo, drogas vegetais amido, gelatinas, dentre outros)(Siuza, 2010);(Pinto, et al., 2015).

A água é muitas vezes o componente mais representativo de formulações farmacêuticas e cosméticas. Por isso, constitui-se uma importante fonte de contaminação. Os sistemas de armazenamento e distribuição de água devem ser periodicamente inspecionados e controlados quanto à contaminação microbiana, particularmente devido à preocupação relacionada à formação de biofilmes. Ainda que a água não faça parte da constituição final do produto, pode ser empregada na lavagem de equipamentos e materiais de embalagem, constituindo-se, neste caso, em fonte indireta de contaminação microbiana(Andrade, 2005). 
A embalagem primária também deve ser considerada como possível fonte de contaminação dos produtos farmacêuticos e cosméticos. Particularmente no caso de produtos estéreis obtidos por processo de manipulação asséptica, devendo ser previamente esterilizados. No caso de materiais de embalagem para produtos não estéreis, devem-se tomar precauções com a contaminação acidental durante o transporte e estocagem. Frascos de vidro podem ser submetidos a tratamento térmico com a finalidade de garantir carga microbiana reduzida. No caso de frascos plásticos termossensíveis, alternativa é proceder com a lavagem dos frascos(Denyer \& Baird, 2007).

Os equipamentos utilizados no processo produtivo (por exemplo, tanques de armazenamento, misturadores, linhas de transferência, dentre outros) podem contribuir indiretamente com a carga microbiana final do produto. Portanto, devem ser sanitizados, desinfectados ou esterilizados antes do uso(Amaral, 2016)(Andrade, 2005).

A qualidade microbiológica do ambiente constitui aspecto de preocupação, particularmente para produtos estéreis obtidos por processo de manipulação asséptica. Neste sentido, a tecnologias de salas limpas assegura ao ambiente condições adequadas para a produção de medicamentos e cosméticos(Pinto, et al., 2015).

O pessoal constitui-se na principal fonte de contaminação microbiana no ambiente de fabricação de medicamentos e cosméticos. Desta forma, o treinamento do pessoal envolvido constitui aspecto importante para minimizar o risco de contaminação acidental do produto. Os usos de barreiras físicas, como luvas, gorros, mascaram, vestimentas e calçados específicos são efetivos, além da higienização de braços e mãos antes do acesso ao ambiente produtivo. Recomenda-se que operador gripado ou com infecções não tenham contato com o produto(Amaral, 2016). 


\subsection{Fatores que afetam contaminação microbiana de medicamentos}

Atualmente, grande importância tem sido dada á questão da conservação microbiológico de medicamentos e cosméticos, não apenas pelo aspecto microbiológico, mas principalmente devido ao potencial de irritação e toxicidade de alguns conservantes apresentam. A controvérsia a respeito da segurança dos conservantes empregados geralmente em medicamentos e cosméticos, e que tem despertado o interesse dos consumidores por produtos com concentrações mínimas de conservantes, com emprego de conservantes naturais (por exemplo, extratos ou óleos essenciais de plantas), ou mesmo livres de conservantes (por exemplo, produtos livres de parabenos) (Pinto, et al., 2015).

É importante destacar que a principal função dos conservantes é inibir o crescimento de microrganismos que, eventualmente, tenham sido introduzidos ao produto durante seu uso. Não é função do conservante compensar a falta de boas práticas durante o processo de fabricação, mas sim garantir que o produto esteja livre de contaminação microbiana durante seu uso, garantindo sua eficácia e segurança. Por este motivo, recomenda-se o uso de conservantes nas concentrações as mais baixas possíveis. $\mathrm{O}$ desenvolvimento de sistemas conservantes com baixas concentrações (para garantir segurança do produto) e que apresentem eficácia antimicrobiana durante todo o prazo de validade do produto não é tarefa fácil (Alves, 2018).

Neste contexto, um sistema conservante efetivo apresenta papel fundamental para garantir a estabilidade, segurança e eficácia de medicamentos e cosméticos. Entre as preparações farmacêuticas, as formas líquidas e semissólidas com base aquosa constituem em aspecto de preocupação, por apresentarem maior probabilidade de contaminação microbiana(Souza, 2017). 
As preparações não estéreis de uso oral (por exemplo, soluções e suspensões orais) ou tópico (por exemplo, cremes e loções), apresentadas na forma de dose múltipla oferecem maior risco de contaminação microbiana durante seu uso. Se considerarmos as preparações estéreis, as formas líquidas e semissólidas compreendem a maioria das preparações parenterais e oftálmicas, respectivamente, cujo conservante tem a finalidade de manter a condição de esterilidade dos produtos. No que diz respeito às formulações cosméticas, estas em sua maioria são preparações semissólidas com base aquosa, necessitando de sistema conservante adequado(Alves, 2018).

O uso de conservantes não é recomendado em produtos de dose única, como por exemplo, comprimidos, cápsulas, injetáveis, entre outros. No caso particular de produtos estéreis, sejam de dose única ou múltipla, a questão da integridade do sistema de fechamento constitui aspecto importante para se garantir a manutenção das condições de esterilidade ao longo do armazenamento e transporte dos produtos(ANVISA, 2010).

Características da formulação, tais como a atividade da água elevada, $\mathrm{pH}$ perto da neutralidade e da presença dos excipientes que poderiam ser usados como fontes nutritivas favorecem o crescimento microbiano em produtos farmacêuticos. Por outro lado, os produtos farmacêuticos com baixa atividade de água, com presença de excipientes com atividade antimicrobiana ou submetidos a altas temperaturas durante o processo de fabricação, são menos susceptíveis à contaminação microbiana(United States Pharmacopeia, 2016).

No que diz respeito ao potencial de oxirredução da formulação, aquelas que apresentam potencial de oxirredução positivo são mais propícias ao crescimento de microrganismos aeróbicos, enquanto as que apresentam potencial de oxirredução negativo são mais susceptíveis ao crescimento de microrganismos anaeróbicos. 


\subsection{Conservação microbiológica de medicamentos}

Atualmente, grande importância tem sido dada a questão da conservação microbiológico dos medicamentos e cosméticos, não apenas pelo aspecto microbiológico, mas principalmente devido ao potencial de irritação e toxicidade de alguns conservantes apresentam. A toxicidade potencial dos conservantes, incluindo a irritação da pele e dos olhos, a sensibilização da pele, os efeitos carcinogênicos e teratogênicos, efeitos no sistema reprodutivo, bioacumulação, e especialmente os efeitos estrogênio tem sido relatados na literatura(Alves, 2018);(Corrêa, 2018).

A controvérsia a respeito da segurança dos conservantes empregados geralmente em medicamentos e cosméticos tem despertado o interesse dos consumidores por produto com conservantes naturais (p.e. óleos essenciais), ou mesmo livres de conservantes (p.e. livres de parabenos) (Pinto, et al., 2015).

É importante destacar que a principal função dos conservantes é inibir o crescimento de microrganismos que, eventualmente, sejam introduzidos ao produto durante seu uso pelo paciente. $\mathrm{O}$ conservante não tem por finalidade eliminar carga microbiana introduzida durante o processo de fabricação em função da falta de boas práticas de fabricação(Alves, 2018).

O desenvolvimento de sistemas conservantes com baixas concentrações (para garantir segurança do produto) e que apresentem eficácia antimicrobiana durante todo o prazo de validade do produto não é tarefa fácil. Um sistema conservante efetivo apresenta papel fundamental para garantir a estabilidade, segurança e eficácia de medicamentos e cosméticos. 
As preparações não estéreis de uso oral ou tópico apresentada na forma de dose múltipla oferecem risco de contaminação microbiana durante seu uso. Se considerarmos as preparações estéreis, as formas líquidas e semissólidas compreendem a maioria das preparações parenterais e oftálmicas, respectivamente, cujo conservante tem a finalidade de manter a condição de esterilidade dos produtos. No que diz respeito às formulações cosméticas, estas em sua maioria são preparações semissólidas com base aquosa, necessitando de sistema conservante adequado. O uso de conservantes não é recomendado em produtos de dose única(ANVISA, 2010)(United States Pharmacopeia, 2016).

O conservante ideal deve apresentar um conjunto de características como: 1) amplo espectro de ação numa faixa ampla de $\mathrm{pH} ; 2$ ) efetividade frente a cepas específicas padrão (ATCC), assim como frente a microrganismos da flora natural (preferencialmente com ação biocida); 3) distribuição adequada entre sistemas emulsionados, quando pertinente; 4) compatibilidade com componentes da formulação e material de embalagem primária; 5) devem ser resistências aos condições de processamento do produto (por exemplo, resistente a esterilização térmica); 6) não interferir na cor, no sabor e no odor do produto; 7) ser atóxico e não irritante; e 8) ter custo aceitável(Pinto, et al., 2015).

Dificilmente um único conservante apresentará todas estas características simultaneamente. Por este motivo, é comum a associação de diferentes conservantes, com a finalidade de potencializar os efeitos com o uso de baixas concentrações de cada componente. Atualmente, existem diversos conservantes disponíveis para uso em medicamentos e cosméticos(Pinto, et al., 2015). 


\subsection{Métodos de análise}

Os métodos de análise envolvendo medicamentos não estéreis e cosméticos abrangem três etapas: 1) amostras, incluindo a coleta, transporte e preparação da amostra para análise; 2) a contagem de microrganismos viáveis presente no produto; e 3) a pesquisa de microrganismos indesejáveis.

\subsubsection{Amostragem}

A amostragem deve ser representativa, considerando-se o número de unidades amostras, o volume contido, assim como as operações unitárias envolvendo risco de contaminação. Quanto pertinente (por exemplo, no caso de amostragem de matériasprimas), a amostragem deve permitir a obtenção de frações da parte inicial, mediana e final do recipiente ou lote(Agência Nacional de Vigilância Sanitária (ANVISA), 2010).

A coleta e o transporte constituem aspecto de preocupação no que diz respeito à integridade da amostra a ser analisada. A coleta deve ser feita em local adequado, por operador treinado, utilizando recipientes e materiais auxiliares (por exemplo, espátulas ou pipetas) estéreis, com a finalidade de não introduzir contaminação à amostra. Tanto o transporte quanto o armazenamento da amostra até o momento da análise devem ocorrer em condições adequadas de temperatura (ANVISA, 2010).

No que diz respeito à quantidade de amostras a ser analisada, a recomendação das principais farmacopéias (brasileira, americana, britânica, européia, japonesa, entre outras) é, geralmente de $10 \mathrm{~g}$ ou $\mathrm{mL}$. Em casos particulares, a tomada de ensaio pode ser reduzida para $1 \mathrm{~g}$ ou $\mathrm{mL}$. 
A preparação da amostra deve, quanto pertinente (por exemplo, quando o produto contém conservantes ou substâncias com atividade antimicrobiana), deve possibilitar a inativação da atividade antimicrobiana do produto, empregando procedimentos de diluição, neutralização química (por exemplo, a adição de polissorbato e lecitina de soja no diluente e meio de cultura para amostras que contenham parabenos como conservantes), filtração, ou ainda uma combinação destes procedimentos(Pinto, et al., 2015).

A homogeneização da amostra, usualmente realizada em agitadores mecânicos (por exemplo, agitados de tubos tipo vortex), deve ser realizada tanto no momento da tomada de ensaio como a cada diluição decimal utilizada.

\subsubsection{Contagem de microrganismos viáveis presente no produto}

A contagem de microrganismos viáveis pode ser realizada empregando-se quatro métodos diferentes: 1) o método de semeadura em profundidade (pourplate);2) o método de semeadura em superfície; 3) o método de filtração em membrana; e 4) o método de tubos múltiplos ou número mais provável (NMP).

O método de semeadura em profundidade consiste na transferência de alíquotas de $1 \mathrm{~mL}$ da amostra, de cada diluição a ser ensaiada, para placas de Petri estéreis (usualmente 2 ou 3 réplicas por diluição). O meio de cultura estéril, fundido e resfriado a temperatura de cerca de $45^{\circ} \mathrm{C}-50^{\circ} \mathrm{C}$, em quantidade de cerca de $20 \mathrm{~mL}$, é vertido sobre cada uma das placas, com subsequente homogeneização (usualmente com movimentos em "8”). As placas são incubadas por 3-4 dias a30-35 C para bactérias (empregando-se meio ágar de caseína-soja - TSA) e por 5-7 dias a $20-25^{\circ} \mathrm{C}$ para bolores e leveduras 
(empregando-se meio Sabouraud dextrose ágar - SDA). Após a incubação, o número de unidades formadoras de colônia (UFC) é contado em cada uma das placas e calcula-se a carga microbiana presente a amostras, considerando-se os fatores de diluição adequados(ANVISA, 2010).

No caso no método de semeadura em superfície, alíquotas de amostras são transferidas com auxílio de pipetas estéreis (entre 0,1 e $0,5 \mathrm{~mL}$ ) para a superfície de meio de cultura (usualmente TSA para bactérias e SDA para bolores e leveduras) previamente distribuído nas placas de Petri. A amostra é espalhada na superfície da placa utilizandose bastão de vidro ou alça de Drigalski estéril. Após incubação, realiza-se a contagem no número de UFC por placa e calcula-se a carga microbiana presente no produto, considerando-se o volume empregado no ensaio(United States Pharmacopeia, 2016).

Quanto o método de filtração em membrana é empregado, alíquotas do produto na forma líquida (ou suas diluições), são filtradas através de membrana esterilizante (usualmente $47 \mathrm{~mm}$ de diâmetro e 0,22 ou $0,45 \mu \mathrm{m}$ de tamanho de poro). Se a amostra apresentar atividade antimicrobiana, recomenda-se lavar a membrana com porções de cerca de $100 \mathrm{~mL}$ de solução fisiológica ou água peptonada $0,1 \%$, para eliminação do resíduo de produto. Em seguida, a membrana é transferida com o auxílio de pinça para a superfície do meio de cultura (usualmente TSA para bactérias e SDA para bolores e leveduras) previamente distribuído nas placas de Petri. Após incubação, procede-se a contagem no número de UFC por placa e calcula-se a carga microbiana presente no produto, considerando-se o volume filtrado e a diluição utilizada(Pinto, et al., 2015).

A determinação do número mais provável (NMP - também conhecido como tubos múltiplos) baseia-se em estimativa do número de microrganismos presentes no produto por meio de cálculos probabilísticos. Neste método, alíquotas de $1 \mathrm{~mL}$ de cada diluição decimal são transferidas para séries de 3 ou 5 tubos de ensaio contendo meio caldo de 
caseína-soja (TSB). Os tubos são incubados por não mais que 3 dias a $30-35^{\circ} \mathrm{C}$. Ao término do período de incubação, os tubos são inspecionados quanto à presença ou ausência de crescimento. A carga microbiana presente no produto é determinada em função do número de tubos com presença de crescimento, utilizando-se uma tabela apropriada (para 3 ou 5 tubos)(Pinto, et al., 2015).

Os quatro métodos apresentados para a contagem de microrganismos viáveis estão descritos nas principais farmacopéias (brasileira, americana, britânica, japonesa, entre outras). Estes métodos apresentam vantagens e limitações, como, por exemplo, a quantidade/representativa da amostra ensaiada (por exemplo, o método de filtração em membrana permite a análise de grandes volumes de amostras, enquanto o método de semeadura em superfície emprega pequenas quantidades de amostra) e a sensibilidade do método (por exemplo, o método de filtração em membrana permite a quantificação de baixas cargas microbianas, enquanto que os métodos de semeadura em profundida e de tubos múltiplos são mais apropriados para amostras com carga microbiana mais elevada)(Agência Nacional de Vigilância Sanitária (ANVISA), 2010)(United States Pharmacopeia, 2016).

\subsubsection{Pesquisa de microrganismos indesejáveis}

Os métodos para pesquisa de microrganismos indesejáveis usualmente empregados para os produtos farmacêuticos estão descritos nas principais farmacopéias (brasileira, americana, britânica, japonesa, entre outras). São métodos tradicionais que envolvem, geralmente, duas etapas: 1) etapa de enriquecimento da cultura microbiana em 
meio não seletivo e 2) etapa de identificação utilizando-se meios de cultura para crescimento seletivo e/ou testes bioquímicos (Denyer \& Baird, 2007).

A etapa de enriquecimento envolve a análise de não menor que $1 \mathrm{~g}$ ou $\mathrm{mL}$ de amostra, sendo utilizado o meio de enriquecimento não seletivo caldo caseína-soja (TSB) incubado por $18-24$ horas a $20-25^{\circ} \mathrm{C}$ e caldo Sabouraud dextrose (SDB),incubado por 35 dias a $30-35^{\circ} \mathrm{C}$. Nos casos particulares da pesquisa de Salmonella e Escherichia coli, procede-se o enriquecimento seletivo empregando-se, respectivamente, os meios Salmonella Rappaport Vassiliadis incubado por $18-48$ horas a $30-35^{\circ} \mathrm{C}$ e caldo MacConkey incubado por $24-48$ horas a $42-44^{\circ} \mathrm{C}$ (Agência Nacional de Vigilância Sanitária (ANVISA), 2010).

Após a etapa de enriquecimento, alíquotas são transferidas com auxílio de alça de esfregaço para os meios seletivos para isolamento e diferenciação, permitindo a identificação do(s) microrganismo(s).

A identificação de Staphylococcus aureus envolve a utilização do meio Ágar Sal de Manitol. O crescimento de colônias amarelas, com halo amarelo, sugere a presença de Staphylococcus aureus no produto. A degradação do manitol a ácido é comprovada pela viragem do indicador de $\mathrm{pH}$ vermelho de fenol (Barban, 2010).

A presença de Pseudomonas aeruginosa no produto pode ser realizada empregando-se três meios diferentes: 1) Ágar cetrimida: crescimento de colônias esverdeadas, com fluorescência, sugere a presença de Pseudomonas aeruginosa; 2) Ágar Pseudomonas para piocianina: crescimento de colônias esverdeadas, com fluorescência azul, sugere a presença de Pseudomonas aeruginosa; e 3) Ágar Pseudomonas para fluoresceína: crescimento de colônias claras e amarelas, com fluorescência amarela, sugere a presença de Pseudomonas aeruginosa (Agência Nacional de Vigilância Sanitária (ANVISA), 2010). 
A identificação de Escherichia coli envolve a utilização de três meios seletivos: 1) Ágar MacConkey: crescimentos de colônias avermelhadas com precipitado de bile sugerem a presença de Escherichia, crescimento de colônias incolores sugere a presença de bactérias lactose-negativas (Salmonellasp.); 2) Ágar Eosina-Azul de metileno (EMB): crescimento de colônias verde-escuras com brilho metálico sugerem presença de Escherichia coli; e 3) Ágar Endo: crescimento de colônias rosadas/vermelhas, com brilho metálico, sugerem a presença de Escherichia coli (United States Pharmacopeia, 2016).

Para a identificação de Salmonellasp. emprega-se o meio seletivo ágar XiloseLisina-Desoxicolato (XLD), que sugere presença de Salmonella sp. no caso de crescimento de colônias vermelhas, com núcleo preto(Barban, 2010).

\subsection{Microrganismos usualmente pesquisados em medicamentos}

\subsubsection{Microrganismos do gênero Enterobacteriacea}

A família Enterobacteriacea é formada por um grande grupo, sendo composta por 44 gêneros e 176 espécies. Enterobacteriacea são bacilos Gram- negativo, não esperulados, que apresentam crescimento na presença ou ausência de oxigênio As enterobactérias são patogênicas para o homem causando vários tipos de doenças, como por exemplo, diarréias, infecções no trato urinário ou respiratório (Barban, 2010).

As bactérias Gram- negativas do gênero Escherichia coli pertencem à família Enterobacteriacea. São aeróbicas ou anaeróbicas e não esperuladas. As células têm forma de bacilos e podem ser imóveis ou móveis por flagelos. Seu crescimento exige condições ótimas de temperatura, $\mathrm{pH}$ e atividade de água(Leme, 2013). 
O habitat natural da Escherichia coli é o trato intestinal dos seres humanos. No entanto, cinco grupos principais podem causar diarréias: as E. coli enteropatogênicas (EPEC), as E. coli enteroagregativas (EAEC), as E. coli de adesão difusa (DAEC) e as $E$. coli enterohemorrágicas (EHEC). Como não aderentes, são identificadas as E. coli enterotoxigênicas (ETEC) e, como invasoras, as E. coli enteroinvasoras (EIEC). Podem causar pneumonia, meningite neonatal e gastroenterite (Barban, 2010)(Leme, 2013).

Usualmente, a identificação das bactérias E.coli ocorre através de provas bioquímicas. As provas de oxidase, hidrólise de uréia e liquefação de gelatina são negativas, enquanto que as provas de lisina são positivas (Agência Nacional de Vigilância Sanitária (ANVISA), 2010)(United States Pharmacopeia, 2016).

O gênero Salmonella é composto por três espécies, sendo Salmonella subterrânea, Salmonella bangori e Salmonella entérica, e pertencem à família Enterobacteriaceae (Ferreira, 2017).As colônias crescem bem nos meios de enterobactérias, à temperatura de $37^{\circ} \mathrm{C}$ e pH entre 4,5 e 9,5. As infecções clínicas humanas determinadas por Salmonella sp. causam gastrenterite, febre entérica, septicemia com ou sem infecções localizadas, tendo a predominância de S. typhimurium (Martins, 2010)(Barban, 2010).

As bactérias do gênero de Salmonella são caracterizadas sorologicamente conforme o seu antígeno somático $(\mathrm{O})$, flagelar $(\mathrm{H})$ e capsular $(\mathrm{V} 1)$, de acordo com o esquema de Kauffmann-White. Os métodos de identificação devem seguir as etapas de pré-enrequecimento, enriquecimento no caldo seletivo, plaqueamento e identificação, confirmação bioquímica e a sua classificação sorológica e sorotipagem (Martins, 2010). 


\subsubsection{Microrganismos do gênero Pseudomonas}

As Pseudomonas pertencem à família denominada de Pseudomonadaceae, com as características de bacilos de Gram-negativoreto ou ligeiramente curvo. Não são esperulados e possuem flagelos polares ou múltiplos. São classificados como não fermentadores, sendo microrganismos aeróbicos, se caracterizam por serem incapazes de utilizar carboidratos como fontes de energia através da fermentação, degradando-os por via oxidativa (Arrud, 1998)(Barban, 2010).

O gênero Pseudomonas possui 140 espécies, e encontra- se mais de 20 espécies nos seres humanos. A espécie $P$. aeruginosa é a mais importante, pois é encontrada em diversos ambientes, principalmente no solo e na água ou ainda associada a plantas e animais. Nos seres humanos, causam infecções hospitalares, em equipamentos para terapia respiratória e em soluções antissépticas. As infecções por Psuedomonas são consideradas infecções oportunistas, sendo capazes de provocar doenças apenas quando o sistema imunológico está comprometido. Desta forma, podem provar infecções cutâneas, urinarias e oculares, pneumonia(Ferreira, 2005)(Baldini, 2010).

A identificação por Pseudomonas ocorre por meio do uso de meios de cultura seletivos, que permitem diferenciar bactérias fermentadoras e não fermentadoras de lactose empregando-se meio de cultura Ágar-sangue, a ausência de fermentação de lactose indica a presença de P.aeruginosa, sendo possível diferenciar o crescimento daquele obtido por bactérias fermentadoras de lactose(Arrud, 1998). 


\subsubsection{Microrganismos do gênero Staphylococcus}

O gênero Staphylococcus pertence à família Staphylococcaceae, e apresentam 32 espécies. O Staphylococcus é microrganismo, possui células com forma esférica, são imóveis e não esporolados. São Gram-positivas, podem ser encontrados isolados sem pares e em grupamentos irregulares, e também são anaeróbios facultativos. Tem a capacidade de crescer em elevado teor de $\mathrm{NaCl}$ (cloreto de sódio - 10\%) e crescem em uma temperatura que varia entre $18^{\circ} \mathrm{C}$ a $40^{\circ} \mathrm{C}($ Bratfich, 2005).

As espécies do gênero de Staphylococcus são divididas em categorias por coagulase positiva e negativa. A atividade desta enzima é utilizada para classificar as espécies como patogênicas e não patogênicas. Assim as espécies coagulase positiva são: $S$. aureus, $S$. delphini e $S$. lutrae, e as coagulase negativa são: $S$. epidermidis, $S$. haemolyticus, S. lugdunensis, S. warneri, S. saprophyticus, entre outros (Ferreira, 2017).

A espécie de $S$. aureus é a mais importante do gênero, podendo causar uma variedade de processos infecciosos em seres humanos, como infecções de pele, em algumas vezes pneumonia, endocardite e osteomielite. Algumas cepas produzem toxinas que provocam gastrenterite, síndrome da pele escaldada e síndrome do choque tóxico. A identificação ocorre por meio da colocação da coloração de Gram e da cultura em meios seletivos (Barban, 2010).

A espécie de S. epidermidis é a segunda mais importante, fazendo parte da flora normal da pele e da mucosa dos seres humanos. É patogênico hospitalar, podendo causar infecções especialmente em pacientes que fazem uso de dispositivos plásticos (cateter e próteses),tendo como característica a resistência á alguns antimicrobianos(Theisen, 2010). 
A identificação de bactérias do gênero Staphylococcus ocorre empregando-se meio cultura, ocorrendo crescimento em meio sólido não seletivo incubados em condições de aerobiose ou anaerobiose, em 24 horas, apresentando-se na forma de colônias grandes, lisas, pigmentadas e com bordas arredondadas. No teste de coagulase em lamina, a superfície da parede celular promove reação com o fibrinogênio,causando a coagulação do mesmo. Entanto que o teste de coagulase em tubos é baseado na presença de coagulase livre que reage com o fator plasmático formando um complexo que atua sobre o fibrinogênio, formando a fibrina (Barban, 2010).

A identificação de S. aureus pode ocorre através do teste do crescimento em ágar manitol, sendo este microrganismo capaz de fermentar o manitol em meio contendo $7,5 \%$ $\mathrm{NaCl}$ e indicador de $\mathrm{pH}$ vermelho de fenol, o que indica uma reação positiva quando o meio ao redor das colônias se torna amarelo e negativa quando permanece avermelhado (Barban, 2010).

\subsection{Etapas envolvidas na pesquisa de microrganismos patogênicos}

Os métodos de identificação microbiano convencional e também conhecidos como tradicional são os mais utilizados e estabelecidos pela Farmacopéia Brasileira. O método tradicional tem duas etapas principais: 1) etapa de enriquecimento da cultura microbiana em meio não seletivo; e 2) etapa de identificação utilizando meio de cultura para crescimento seletivo. 


\subsubsection{Etapa de enriquecimento da cultura microbiana em meio não seletivo}

A etapa de enriquecimento tem por finalidade proporcionar o aumento da massa celular empregando-se meio de cultura de composição rica não seletiva. Recomenda-se a realização subsequente do método de coloração de Gram, para identificação morfológica (cocos ou bacilos) do microrganismo e sua classificação como Gram-positivo ou Gramnegativo.

O método de coloração de Gram é muito importante na microbiologia. Esse método tem objetivo de conseguir identificar a morfologia geral através coloração simples e na coloração diferenciais é capaz de descriminar a espécie ou grupos determinados. Com o processo de esfregaço fixado, ocorrem as seguintes etapas na coloração de Gram:

- Adição de solução de Cristal violeta

- Adição de solução Lugol (fixador do corante)

- Lavagem com etanol (bactéria Gram-negativas sofrem descoloração enquanto as Gram-positivas não).

- Adição de solução de safranina.

Após o processo é observado à mudança da coloração, sendo visível a cor roxa para bactérias Gram-positivas, devido à reativação violeta-lugol. Para microrganismos Gram-negativos,observa-se a coloração rósea-vermelha devido à fixação do corante safranina (Barbosa, et al., 2018). 


\subsubsection{Etapa de identificação utilizando meio de cultura seletivo}

O meio seletivo propicia o crescimento do microrganismo de interesse (a ser identificado/pesquisado), podendo se empregar provas bioquímicas. Dentre as principais provas bioquímicas empregadas na identificação microbiana destacam-se(United States Pharmacopeia, 2016)(Franzolin, 2004):

- Prova Catalase: é uma enzima que decompõe o peróxido de hidrogênio $\left(\mathrm{H}_{2} \mathrm{O}_{2}\right)$ em oxigênio e água. É utilizado para diferenciação de Staphylococcous e Micrococcocus.

- Prova Citocromo-Oxidase: é a enzima que oxida o citocromo C. Encontra-se em aeróbico e anaeróbico facultativo. Esse teste é negativo para a família Enterobacteriaceae e para outros gêneros não fermentadores como Pseudomonas são positivas.

- Prova de Oxidação-Fermentação: é usada para determinar se um organismo pode utiliza carboidratos de forma oxidativa ou fermentativa. Sendo a reação positiva é indicada pela coloração amarela e a negativa com coloração verde ou azul.

- Prova de Coagulase: a bactéria produz a enzima coagulase, com a presença do plasma provoca a coagulação. É utilizada para diferenciar o $S$. aureus de outras espécies.

- Fermentação de Açúcar: consiste em detectar a acidificação do meio de cultura com o indicador do pH. Pois na reação de fermentação de açúcares ocorre a formação de ácidos orgânicos metabolitos, desta forma diminuindo o $\mathrm{pH}$ do meio. 
- Prova do Vermelho de Metila: para identificar bactérias que produzem ácidos orgânicos, ocorre a fermentação de glicose e assim mantendo a cor vermelha de metila.

- Prova Voges- Proskauer: fermentação de glicose com produção de acetoína. O acetil é convertido diacetil, que é convertido em um complexo vermelho pela ação catalítica de $\alpha$-naftol e creatina.

- Prova de Indol: As bactérias que possuem a enzima triptofanase são capazes de hidrolisar.

- Prova de Citrato: é um composto orgânico simples encontrado no ciclo de Krbes. Algumas bactérias podem obter energia do citrato, assim sendo uma característica especifica M.O. Desta forma a catalase negativa para E.coli, mas é catalse positiva para Klebisella.

- Prova de Urease: é uma enzima que hidrolisa a ureia em amônia e dióxido de carbono, ocorre o aumento do pH e consequentemente altera coloração.

- Prova de Fenilalanina Desaminase: a desaminação de fenilalanina forma ácido fenilpirúvico. Apenas as espécies de Proteus, Morganella e Providencia que possuem para a desaminação de fenilalanina.

- Prova de DNASE: é usado para detectar a atividade da enzima desoxirribonuclease produzidas por diferentes espécies bacterianas. Sendo utilizada para diferenciar o Staphylococcous aureus de outras espécies.

- Lisina: é utilizado para identificação de Enterobacteriaceae. Utiliza o meio Moeller acrescentando-se aminoácido, e contém o indicador $\mathrm{pH}$ púrpura de bromocresol, em pH ácido é amarelo e $\mathrm{pH}$ alcalino é púrpura. Ocorre à reação anaerobiose, assim o meio é coberto por uma camada de óleo mineral estéril. 
- Optoquina: é um derivado de quinina e inibe seletivamente o crescimento S.pneumoniae.

- Prova de Motilidade: é realizada a partir do crescimento em meio semissólido e quantidade de ágar presente no meio varia para cada grupo de bactéria.

- Redução Nitrato: é capacidade de um organismo reduzir o nitrato a nitrito, sendo uma importante característica para vários grupos de microrganismo.

- Produção Sulfeto de Hidrogênio H2S: algumas bactérias são capazes de formar $\mathrm{H}_{2} \mathrm{~S}$ a partir do aminoácido ou outros compostos contém enxofre. Sendo uma característica importante para identificação.

- Manitol: é utilizado para identificação S.aureus, com a presença do manitol produz colônias amarelas circundadas por halo da mesma cor.

- PYR: são utilizados para identificação provável Estreptococos $\beta$-hemodialise.

\subsection{Adequação dos métodos de contagem de microrganismos viáveis e de} pesquisa de microrganismos indesejáveis

A avaliação dos métodos de contagem de microrganismos viáveis e de pesquisa de microrganismos indesejáveis quanto à sua adequação abrange: 1) emprego de controle negativo; 2) a confirmação da capacidade promotora de crescimento os meios de cultura; e 3) a determinação da recuperação dos microrganismos-teste na presença de produto (United States Pharmacopeia, 2016).

Durante a verificação da adequabilidade do método de contagem de microrganismos viáveis e de pesquisa de microrganismos indesejáveis, deve-se empregar 
controle negativo, de forma a verificar as condições do teste. $\mathrm{O}$ controle negativo não deve apresentar crescimento. Em caso de falha do controle negativo, a verificação da adequabilidade dos métodos deve ser repetida.

Cada lote de meio de cultura recém-preparado deve ser avaliado quanto a sua capacidade promotora de crescimento. Esta avaliação consiste na inoculação de cerca de 100 UFC de microrganismos-teste em tubos ou placas de Petri com os meios avaliados. Para meios sólidos, a quantidade recuperada deve estar entre 50 e $200 \%$ da quantidade inoculada. Nos casos de meios de cultura líquidos, estes podem ser considerados aprovados quanto apresentam crescimento visível comparável a lotes anteriores (Pinto, et al., 2015).

A determinação da recuperação de microrganismos na presença de produto consiste em adicionar à amostra diluída e ao controle (diluente sem amostra) quantidade de suspensão microbiana suficiente para se obter cerca de $100 \mathrm{UFC} / \mathrm{mL}$. O número de microrganismos na amostra deve ser comparável (entre 50 e 200\%) ao número de microrganismos no controle. Caso a recuperação seja baixa (menor que 50\%), devem ser realizadas alterações no procedimento de contagem para assegura a validade do resultado, tais como: 1) diluição do produto; 2) adição de agentes neutralizantes específicos; 3) filtração do produto; ou 4) combinação de 2 ou 3 dos procedimentos anteriores (Agência Nacional de Vigilância Sanitária (ANVISA), 2010).

Para determinar a recuperação de microrganismos na presenta de produto, adiciona-se suspensão microbiana em quantidade suficiente para se obter cerca de 100 UFC/mL numa amostra diluída exatamente como o teste será realizado(Agência Nacional de Vigilância Sanitária (ANVISA), 2010).

Os microrganismos-teste usualmente empregados, tanto na confirmação da capacidade promotora de crescimento dos meios quanto na determinação da recuperação 
de microrganismos na presenta de produto, são Staphylococcus aureus (ATCC 6538), Pseudomonas aeruginosa (ATCC 9027), Bacillus subtilis (ATCC6633), Candida albicans (ATCC 10231) e Aspergillus brasiliensis (ATCC 16404).

\subsection{Métodos microbiológicos alternativos}

Os métodos microbiológicos rápidos (MMRs) têm sido desenvolvidos como alternativas aos métodos microbiológicos tradicionais para a análise quantitativa e qualitativa dos alimentos, cosméticos, medicamentos e amostras clínicas (Easter, 2003) (Pinto, et al., 2015).Os métodos microbiológicos rápidos (MMRs) possuem algumas vantagens em comparação com os métodos tradicionais, por exemplo, o aumento facilidade de registros, a rastreabilidade dos dados e a redução das etapas envolvidas e do tempo pela obtenção de resultados.

O MMR deve ser escolhido tendo em conta a finalidade do ensaio e a compatibilidade com o produto. Os principais métodos são:

- Métodos baseados no crescimento: métodos eletroquímicos, bioluminescência, detecção da produção ou consumo de gás e emprego de substratos cromogênicos.

- Métodos de viabilidade: coloração para componentes bioquímicos de células microbiológicas, técnicas de citometria em fluxo, citometria de fase sólida e epifluorescência direta.

- Métodos de análise fenotípica: técnicas imunológicas com a finalidade de detectar e quantificar os microrganismos por meio de interação antígeno-anticorpo. Também podem ser utilizadas técnicas para avaliação do perfil de ácidos graxo, 
técnicas de espectrometria no infravermelho (FTIR), espectroscopia em massa (MALDI-TOF).

- Métodos de análise genotípica: é um método analise direta do DNA. Também abrange o uso de tecnologias de amplificação de ácidos nucléicos (PCR) e impressões digitais (fingerprint).

Apesar das vantagens dos métodos microbiológicos rápidos (MMR), ainda existem algumas barreiras, principalmente devido a questões regulatórias. A validação do método é etapa fundamental para a aprovação do MMR pelas agências regulatórias.

\subsubsection{Validação de MMRs}

Na validação de MMRs, tem-se quatro componentes modelo, sendo a qualificação de delineamento, instalações, operacional e performance. Consiste em garantir que o equipamento está apropriado para o uso pretendido, assegurando que todo sistema envolvido seja avaliado incluindo hardware, software, reagente e aplicações do método.

Devem ser avaliados os parâmetros de validações, que envolvem:

- Exatidão: Este parâmetro é utilizado para ensaios quantitativos. A exatidão é a proximidade dos resultados obtidos pelo método em estudo em relação ao valor verdadeiro.

- Precisão: medida da variabilidade dos resultados, através da determinação do desvio padrão (ou desvio padrão relativo) obtidos a partir análises repetidas de amostras, em condições de repetibilidade, precisão 
intermediária ou reprodutibilidade. Este parâmetro é avaliado para ensaios quantitativos.

- Especificidade: é a capacidade de detectar microrganismos, demonstrando que o método é adequado para a finalidade.

- Limite de quantificação: é o menor número de microrganismo que pode ser determinado com precisão e exatidão aceitáveis. Este parâmetro é utilizado para ensaios quantitativos.

- Limite de detecção: é aplicável para métodos microbiológico quantitativo e qualitativo. É o menor número de microrganismo presente na amostra, consegue serem em detectadas nas condições experimentais estabelecidas.

- Linearidade: Este parâmetro é utilizado para ensaios quantitativos. Esse teste determina a sua capacidade de obter resultados proporcionais à concentração de microrganismos presente na amostra, dentro de um determinado intervalo.

- Intervalo: É o intervalo entre o maior ou o menor nível de microrganismo no qual foram demonstradas precisão, exatidão e linearidade. Este parâmetro é utilizado para ensaios quantitativos.

- Resistência: é o grau de reprodutibilidade dos resultados obtidos no teste por análise da mesma amostra sob as variações das condições normais do teste, como diferentes analistas, instrumentos e lotes de reagentes.

- Robustez: é a medida resistência em se manter inalterado com sob as variações dos parâmetros analíticos, como a temperatura de incubação e parâmetros de operações equipamentos. 
- Repetibilidade: é o grau de concordância entre as réplicas de ensaios dentro curto período tempo com o mesmo analista e instrumento. Sendo aplicável para métodos microbiológico quantitativo e qualitativo.

- Equivalência: é a medida da similaridade entre os resultados do teste convencional e aqueles obtidos pelo MMR. A comparação do MMR com o método convencional faz-se necessária com a finalidade de demonstrar sua equivalência.

Considerando-se as vantagens do desenvolvimento, validação e implementação dos métodos microbiológicos rápidos (MMRs), devemos destacar a redução tempo para liberação do produto, redução de estoque de matérias-primas e produtos acabados, melhoria na qualidade dos testes microbiológicos, automatização dos testes microbiológicos, captura eletrônica de dados de teste / geração de informação, capacidade de iniciar as investigações precocemente em resposta a resultados fora especificações, potencial de redução de risco de contaminações microbianas dos produtos e melhoria nos processo de fabricação(Pinto, et al., 2015).

\subsection{Espectrometria no infravermelho}

Dentre as diversas técnicas analíticas que permitem a rápida identificação microbiana em diversas matrizes de amostras (tais como alimentos e amostras biológicas com finalidade clínica), destaca-se a espectrofotometria no infravermelho. Nesta técnica, a frequência da radiação absorvida corresponde aquela que fornece energia para a vibração molecular. A absorção do infravermelho está restrita a espécie molecular que tem diferenças de energias entre os estados vibracionais e rotacionais. $\mathrm{O}$ espectro 
infravermelho de absorção, emissão, e reflexão de espécies moleculares se origina de diversas variações de energia causadas por transições de moléculas de um estado vibracional ou rotacional de energia para outra. A região do espectro pode variar nas radiações do infravermelho próximo (12.800 à $\left.4.000 \mathrm{~cm}^{-1}\right)$, médio $\left(4.000\right.$ à $\left.200 \mathrm{~cm}^{-1}\right)$ e distante (200 à $\left.10 \mathrm{~cm}^{-1}\right)$ (Paiva, 2010).

$\mathrm{Na}$ espectrofotometria de infravermelho (FTIR) com reflectância total atenuada (ATR), o feixe de luz é direcionado a um ângulo específico e passa através de cristal em direção a amostra. Desta forma, o feixe de luz penetrará uma camada fina da superfície da amostra absorvente e sofrerá uma perda de energia naqueles comprimentos de onda em que o material absorve. A vantagem da FTIR-ATR é que a potência da radiação que atinge o detector é maior que aquela de aparato dispersivo, sendo observada melhor relação sinal-ruído e alto poder de resolução (SKOOG, 2002).

\subsection{Ferramentas estatísticas usualmente empregadas em quimiometria}

$\mathrm{Na}$ espectrofotometria de infravermelho (FTIR) com reflectância total atenuada (ATR) é também utilizada para classificação e identificação de microrganismo. Ao aplicar nas células de microrganismos o espectro de infravermelho reflete a composição bioquímica qualitativa da célula, assim podem ser identificadas as composições, sendo as proteínas, ácidos nucléicos, lipídios, carboidratos e DNA/RNA. Desta forma, cada banda corresponde uma estrutura molecular. Na Tabela 1 demonstra as principais estruturas moleculares encontradas através no espectro de infravermelho por ATR (Naumann, 2000)(Ferreira, 2017). 
Tabela 1. Atribuição das bandas frequentemente encontradas nos espectros IR microbianos. (adaptado de Joana \& DieterNaumann)

\begin{tabular}{|c|c|}
\hline Número de ondas & Designação \\
\hline $900-600$ & Região impressão digital (fingerprint) \\
\hline 720 & Vibração da rotação da ligação C-H de $>\mathrm{CH}_{2}$ \\
\hline 1085 & $\mathrm{P}-\mathrm{O}$ simétrica de $>\mathrm{PO}_{2}$ \\
\hline $900-1200$ & C-O-C, C-O vibração de carboidratos \\
\hline $1250-1220$ & $\mathrm{P}=\mathrm{O}$ assimetria de $>\mathrm{PO}_{2}$ de fosfodiésteres \\
\hline $1310-1240$ & Banda amida III das proteínas \\
\hline$\sim 1400$ & $\mathrm{C}=\mathrm{O}$ simétrica de $\mathrm{COO}$ \\
\hline 1468 & $\mathrm{C}-\mathrm{H}$ deformação $>\mathrm{CH}_{2}$ \\
\hline 1515 & Banda de Tirosina \\
\hline $1520-1550$ & Banda amida II \\
\hline$\sim 1637$ & Estrutura das folhas $-\beta$ da amida I \\
\hline$\sim 1655$ & Estrutura $\alpha$-helicoidais da amida I \\
\hline$\sim 1675$ & Resultante de folha B-antiparalela \\
\hline$\sim 1685$ & Configuração $\beta$ das proteínas \\
\hline$\sim 1695$ & Componente da banda da amida I \\
\hline $1680-1715$ & $>\mathrm{C}=\mathrm{O}$ dos ácidos nucléicos \\
\hline 1715 & $>\mathrm{C}=\mathrm{O}$ dos ácidos carbônicos $-\mathrm{C}=\mathrm{O}-\mathrm{OH}$ \\
\hline 1740 & $>\mathrm{C}=\mathrm{O}$ grupo ésteres \\
\hline 2850 & $\mathrm{C}-\mathrm{H}$ simétrico de $>\mathrm{CH}_{2}$ \\
\hline 2870 & $\mathrm{C}-\mathrm{H}$ simétrica de $-\mathrm{CH}_{3}$ \\
\hline 2898 & C-H em grupo de metilo \\
\hline 2921 & $\mathrm{C}-\mathrm{H}$ assimetria de $>\mathrm{CH}_{2}$ ácidos graxos \\
\hline 2930 & $\mathrm{C}-\mathrm{H}$ assimetria de $>\mathrm{CH}_{2}$ \\
\hline 2955 & $\mathrm{C}-\mathrm{H}$ assimetria de $-\mathrm{CH}_{3}$ \\
\hline$\sim 3200$ & N-H das proteínas \\
\hline$\sim 3500$ & O-H grupo hidroxilo \\
\hline
\end{tabular}




\subsubsection{Análise Componente Principal (PCA)}

Análise Componente Principal é uma técnica multivariada surgiu em 1933, desenvolvida por Hotelling com a finalidade em analisar as estruturas de correlações entre os dados. PCA é uma técnica conhecida e amplamente empregada com a finalidade de reduzir o número de variáveis com menor perda possível da informação. Assim, PCA consiste em transformar um conjunto de variáveis originais em outro conjunto de variáveis das mesmas dimensões denominadas de componente principal. O PCA substitui um modelo com muitas variáveis independentemente por poucas variais dependentes (componentes) originadas pela combinação linear das variáveis originais. Dessa forma o PCA permite a organização de dados de tal maneira que os primeiros componentes expliquem o maior número possível de informações disponíveis, facilitando a visualização de dados e simplificando análise(Hongyu, et al., 2015)(Paiva, 2006).

\subsubsection{Análise Discriminante Linear (LDA)}

A análise discriminante linear (LDA) é uma técnica estatística multivariada com a finalidade discriminar e classificar objetos, ou seja, é uma técnica que permite estudar as diferenças entre dois ou mais grupo de objetivos. O objetivo da análise discriminante é indicar a significâncias relativas das variáveis preditivas, quando o número delas é muito grande. A idéia principal da LDA é baseada em determinar se os grupos são diferentes com relação à medida de uma variável, e então usar essa variável para prever ao qual grupo uma nova observação desconhecida pertence (Varella, 2010). 

JUSTIFICATIVA 



\section{JUSTIFICATIVA}

Considerando as limitações dos métodos microbiológicos convencionais e as vantagens dos MMRs, faz-se necessário o desenvolvimento de métodos para a identificação rápida de contaminantes em produtos farmacêuticos. Os métodos espectroscópicos são alternativas interessantes, pois apresentam vantagens tais como:

- Redução no número de etapas envolvidas na identificação microbiana;

- Obtenção de resultados rápidos;

- Maior possibilidade de automação;

- Maior facilidade no registro e rastreabilidade dos dados;

- Redução dos custos analíticos durante a análise de rotina. 



\section{OBJETIVOS}





\section{OBJETIVOS}

\subsection{Objetivo Geral}

Desta forma, este trabalho tem o objetivo de desenvolver método microbiológico rápido (MMR) para a identificação de contaminantes microbianos em produtos farmacêuticos, utilizando a técnica de espectrometria no infravermelho por reflectância total atenuada (FTIR-ATR).

\subsection{Objetivo Específico}

O projeto tem o objetivo de validar um novo MMR conforme os parâmetros: sensibilidade/especificidade, limite de detecção, resistência, robustez e repetibilidade.

O MMR será comparado com o método tradicional quanto a sua equivalência na análise de formas farmacêuticas orais e tópicas.

Estabelecer modelo de predição capaz de diferenciar os microrganismos presentes em produtos farmacêuticos e possibilitar a constatação da presença/ausência dos principais contaminantes (Salmonella sp, Escherichia coli, Staphylococcus aureus e Pseudomonas aeruginosa). 

MATERIAIS E MÉTODOS 



\section{5 . MATERIAIS E MÉTODOS}

\subsection{Materiais}

\subsubsection{Meios de cultura}

- Ágar Cetrimide (digesto pancreático de gelatina 20,0 g/L, cloreto de magnésio $1,4 \mathrm{~g} / \mathrm{L}$, sulfato de potássio dibássico $10,0 \mathrm{~g} / \mathrm{L}$, cetrimida 0,3 g/L, ágar 13,6 g/L e glicerol 10,0 mL/L);

- Ágar de caseína-soja (TSA) (digesto pancreático de caseína 17,0 g/L, digesto papáico de soja 3,0 g/L, glicose 2,5 g/L, cloreto de sódio 5,0 $\mathrm{g} / \mathrm{L}$ e ágar17 g/L);

- Ágar MacConkey (digesto pancreático de gelatina 17,0 g/L, peptonas de carne e caseína 3,0 g/L, lactose monoidratada 10,0 g/L, cloreto de sódio 5,0 g/L, sáis biliares 1,5 g/L, ágar 13,5 g/L, vermelho neutro 30,0 $\mathrm{mg} / \mathrm{L}$ e cristal violeta $1 \mathrm{mg} / \mathrm{L})$;

- Ágar Sal de Manitol (digesto pancreático de caseína 5,0 g/L, digesto peptídico de tecido animal 5,0 g/L, extrato de carne 1,0 g/L, manitol 10,0 g/L, cloreto de sódio 75,0 g/L, ágar 15,0 g/L e vermelho fenol 25 $\mathrm{mg} / \mathrm{L})$;

- Caldo de caseína-soja (TSB) (digesto pancreático de caseína 17,0 g/L, digesto papáico de soja 3,0 g/L, glicose 2,5 g/L, cloreto de sódio 5,0 $\mathrm{g} / \mathrm{L}$ e fosfato de potássio dibásico $2,5 \mathrm{~g} / \mathrm{L})$;

- Solução de cloreto de sódio (cloreto de sódio 9,0 g/L). 


\subsubsection{Microrganismos}

- Bacillus subtilis(ATCC 6633);

- Candida albicans (ATCC 10231);

- Enterococcus faecium (ATCC 8459);

- Escherichia coli (ATCC 8739);

- Micrococcus luteus (ATCC 10240);

- $\quad$ Pseudomona aeruginosa (ATCC 9027);

- $\quad$ Salmonella Typhimurium (ATCC 14028);

- Staphylococcus aureus (ATCC 6538);

- Staphylococcus epidermidis (ATCC 12228);

\subsubsection{Equipamentos}

- Autoclave vertical;

- Balança analítica

- Balança semi-analítica

- Centrífuga;

- Espectrofotômetro de absorção no infravermelho com transformada de Fourier, equipado com aparato de reflectância total atenuada (FTIRATR);

- Estufa bacteriológica;

- pHmetro. 


\subsubsection{Outros materiais}

- Alças de cultura estéreis descartáveis;

- Pipetas graduadas estéreis descartáveis;

- Pipetas Pasteur estéreis descartáveis;

- Placas de Petri estéreis descartáveis;

- Tubos de ensaios estéreis descartáveis.

\subsection{Preparação e pré-incubação das amostras de produtos farmacêuticos}

Produtos farmacêuticos (A: solução oral de paracetamol, B: solução oral de dipirona, C: solução tópica de Digluconato de clorexidina) foram intencionalmente contaminados com $10^{2}-10^{3}$ UFC (unidades formadoras de colônia) de Bacillus subtilis (ATCC 6633), Candida albicans (ATCC 10231), Enterococcus faecium (ATCC 8459), Escherichia coli (ATCC 8739), Micrococcus luteus (ATCC 10240), Pseudomonas aeruginosa (ATCC 9027), Salmonella Typhimurium (ATCC 14028), Staphylococcus aureus (ATCC 6538), e Staphylococcus epidermidis (ATCC 12228) (A: $\mathrm{n}=5 ; \mathrm{B}: \mathrm{n}=5$; e $C: n=5)$.

Alíquotas de $10 \mathrm{~mL}$ de os produtos farmacêuticos foram transferidas para $90 \mathrm{~mL}$ de solução esterilizada de cloreto de sódio $0,9 \%$, agitados e filtrados por uma membrana de éster de celulose estéril de $0,45 \mu \mathrm{m}$. As membranas foram transferidas assepticamente para tubos de ensaio contendo $10 \mathrm{ml}$ de caldo de caseína-soja (TSB). Os tubos de ensaio foram incubados em estufa bacteriológica para $18-24 \mathrm{~h}$ a $37 \pm 1^{\circ} \mathrm{C}$.

As suspensões microbianas obtidas após a incubação foram analisadas empregando-se tanto os testes microbiológicos convencionais para identificação de 
microrganismos patogênicos como o método de espectrometria no infravermelho com transformada de Fourier com reflectância total atenuada (FTIR-ATR).

\subsection{Métodos microbiológicos convencionais para a identificação microbiana}

Todos os testes microbiológicos convencionais para a identificação de microrganismos patogênicos foram realizados de acordo com o capítulo $<62>$ "Microbial examination of non sterile products: tests for specified microorganisms" da farmacopeia americana (United States Pharmacopeia, 2016).

As alíquotas de crescimentos microbiológicos foram transferidas para meios de cultura seletiva usando-se alças estéreas descartáveis. Os meios de cultura ágar MacConkey, ágar Cetrimida e ágar sal de manitol foram empregados para a identificação dos microrganismos patogênicos Escherichia coli, Pseudomonas aeruginosae, Staphylococcus aureus, respectivamente.

As respostas de crescimento esperados de Bacillus subtilis (ATCC 6633), Candida albicans (ATCC 10231), Enterococcus faecium (ATCC 8459), Escherichia coli (ATCC 8739), Micrococcus luteus (ATCC 10240), Pseudomonasaeruginosa (ATCC 9027), Salmonella Typhimurium (ATCC 14028), Staphylococcus aureus (ATCC 6538) e Staphylococcus epidermidis (ATCC 12228) nos meios ágar MacConkey, ágar Cetrimida e ágar sal de manitol estão apresentadas na Tabela2. 
Tabela 2. Respostas de crescimento esperados de Bacillus subtilis (ATCC 6633), Candida albicans (ATCC 10231), Enterococcus faecium (ATCC 8459), Escherichia coli (ATCC 8739), Micrococcus luteus (ATCC 10240), Pseudomonas aeruginosa (ATCC 9027), Salmonella Typhimurium (ATCC 14028), Staphylococcus aureus (ATCC 6538) e Staphylococcus epidermidis (ATCC 12228) nos meios ágar MacConkey, ágar Cetrimida e ágar sal de manitol.

\begin{tabular}{llll}
\hline Microrganismo & ÁgarMacConkey & ÁgarCetrimida & Ágarsal de mannitol \\
\hline B. subtilis & Sem crescimento & Sem crescimento & Sem crescimento
\end{tabular}

C. albicans

Sem crescimento

E. faecium

E. coli

M. luteus

P. aeruginosa

S. aureus

S. epidermidis
Sem crescimento

Sem crescimento

Bom crescimento,

Colônias amarelas

Bom crescimento, colônias amarelas

Sem crescimento

Sem crescimento
Sem crescimento
Sem crescimento

Sem crescimento
Sem crescimento

Crescimento inibido

Crescimento inibido
Sem crescimento

Bom crescimento, colônias esverdeadas a azul

Sem crescimento

Crescimento inibido
Bom crescimento, colônias amarelas

Bom crescimento, colônias vermelhas 


\subsection{Espectrometria no infravermelho com transformada de Fourier com reflectância total atenuada (FTIR-ATR)}

As suspensões microbianas de crescimento obtidas a partir de produtos farmacêuticos usando caldo de caseína-soja (TSB) foram centrifugadas a 1.500 RPM por 60 minutos. Os sobrenadantes dos meios de cultura foram eliminados e as biomassas foram utilizadas para as determinações em espectrometria (Figura 1).

Os espectros das biomassas foram obtidos utilizando o equipamento de espectrômetro infravermelho com transformada de Fourier equipado com aparato de reflectância total atenuada (FTIR-ATR), com a de transmissão na região entre 4.000 e $550 \mathrm{~cm}^{-1}$ E foram obtidos partir de 32 determinações, e os valores médios foram usados durante a análise de dados.

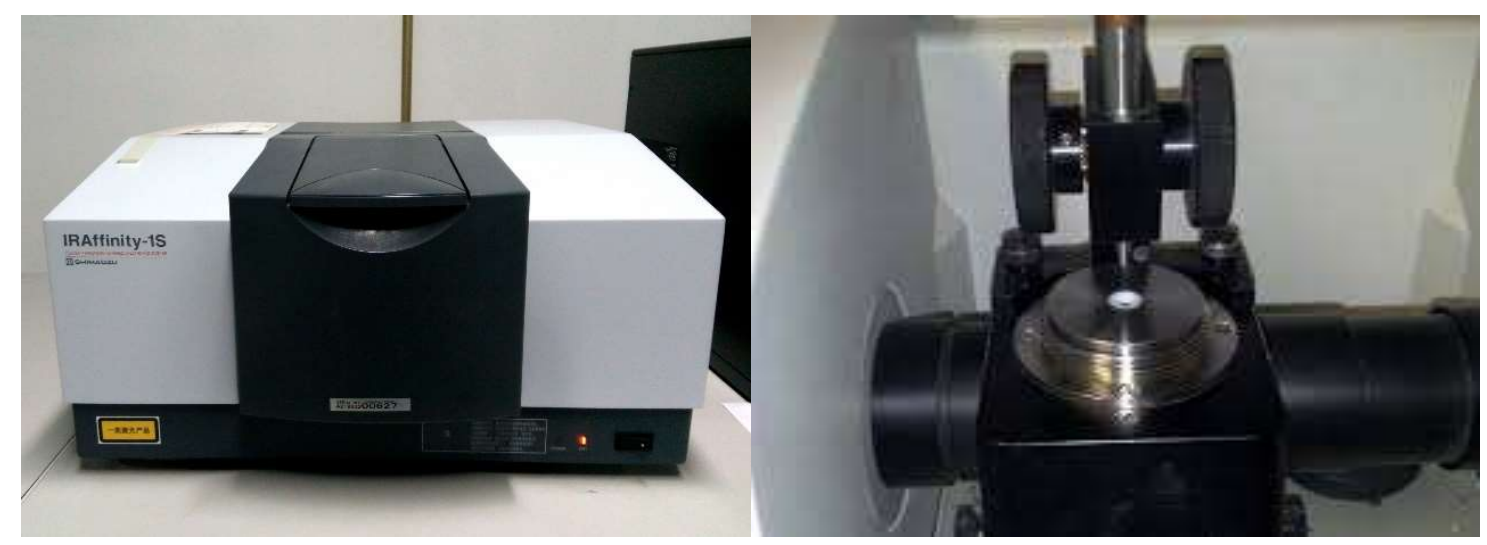

Figure 1. Espectrofotômetro infravermelho com transformada de Fourier (FTIR) (esquerda) e aparato de reflectância total atenuada (ATR) (direita) utilizados nas determinações dos espectros das biomassas na região entre 4.000 e $550 \mathrm{~cm}^{-1}$. 


\subsection{Análise dos dados}

As análises de componentes principais (PCA), análises de discriminante (LDA), validação cruzada e validação externa foram realizadas usando o software Minitab $^{\mathrm{TM}} 17$. Os espectros foram tratados matematicamente, de forma a se obter a primeira derivada suavizada na região entre 2.000 e $800 \mathrm{~cm}^{-1}$, e posteriormente utilizados nas análises de PCA e LDA.

Os modelos de previsões foram construídos a partir de 120 espectros de Bacillus subtilis (ATCC 6633), Candida albicans (ATCC 10231), Enterococcus faecium (ATCC 8459), Escherichia coli (ATCC 8739), Micrococcus luteus (ATCC 10240), Pseudomonas aeruginosa (ATCC 9027), Salmonella Typhimurium (ATCC 14028), Staphylococcus aureus (ATCC 6538) e Staphylococcus epidermidis (ATCC 12228), tendo $\mathrm{n}=20$ para cada microrganismo e obtendo a partir dos resultados de PCA e LDA.Os mesmos 120 espectros foram utilizados na validação cruzada (interna), empregando-se o método do "leave-one-out".

Adicionalmente, 108 espectros de Bacillus subtilis (ATCC 6633, $\mathrm{n}=10$ ), Candida albicans (ATCC 10231, $\mathrm{n}=10$ ), Enterococcus faecium (ATCC 8459, $\mathrm{n}=14$ ), Escherichia coli (ATCC 8739, $\mathrm{n}=15)$, Micrococcus luteus $($ ATCC 10240, $\mathrm{n}=13$ ), Pseudomonas aeruginosa (ATCC 9027, $\mathrm{n}=13$ ), Salmonella Typhimurium (ATCC 14028, $\mathrm{n}=5$ ), Staphylococcus aureus (ATCC 6538, $\mathrm{n}=14$ ) e Staphylococcus epidermidis (ATCC 12228, $\mathrm{n}=14$ ) foram utilizados na validação externa. 


\subsection{Validação do método FTIR-ATR para identificação microbiana rápida}

O método FTIR-ATR para identificação rápida de contaminantes microbianos em produtos farmacêuticos foi validado avaliando-se sua sensibilidade e especificidade. A sensibilidade foi determinada como a proporção do número de resultados positivos obtidos usando o método FTIR/ATR e o número de produtos que apresentaram crescimento microbiano. Por outro lado, especificidade foi determinada como a proporção de amostras não contaminadas intencionalmente e o número de amostras que não apresentaram crescimento microbiano.

Além disso, FTIR-ATR método será validado, avaliando-se o limite de detecção. Os crescimentos microbianos de cada microrganismo foram obtidos após a incubação durante $18-24 \mathrm{~h}$ a $37 \pm 1^{\circ} \mathrm{C}$. Diluições decimais seriadas foram preparadas usando-se TSB. Alíquotas de cada diluição foram transferidas para placas de Petri, e 15-20 ml de TSA fundido (cerca de $45^{\circ} \mathrm{C}$ ) foi transferido e para os tubos de ensaios. Tubos de ensaio e placas de Petri foram incubados em estufa bacteriológica para $18-24 \mathrm{~h}$ a $37 \pm 1^{\circ} \mathrm{C}$. Os tubos de ensaio foram inspecionados quanto à presença/ausência de crescimento microbiano. O número de UFC (unidades formadoras de colônia) foi contado manualmente a partir de placas de Petri. O limite de detecção foi determinado como o número de UFC obtido a partir do último tubo de diluição decimal com presença de crescimento microbiano, conforme a apresentada na Figura 2. 


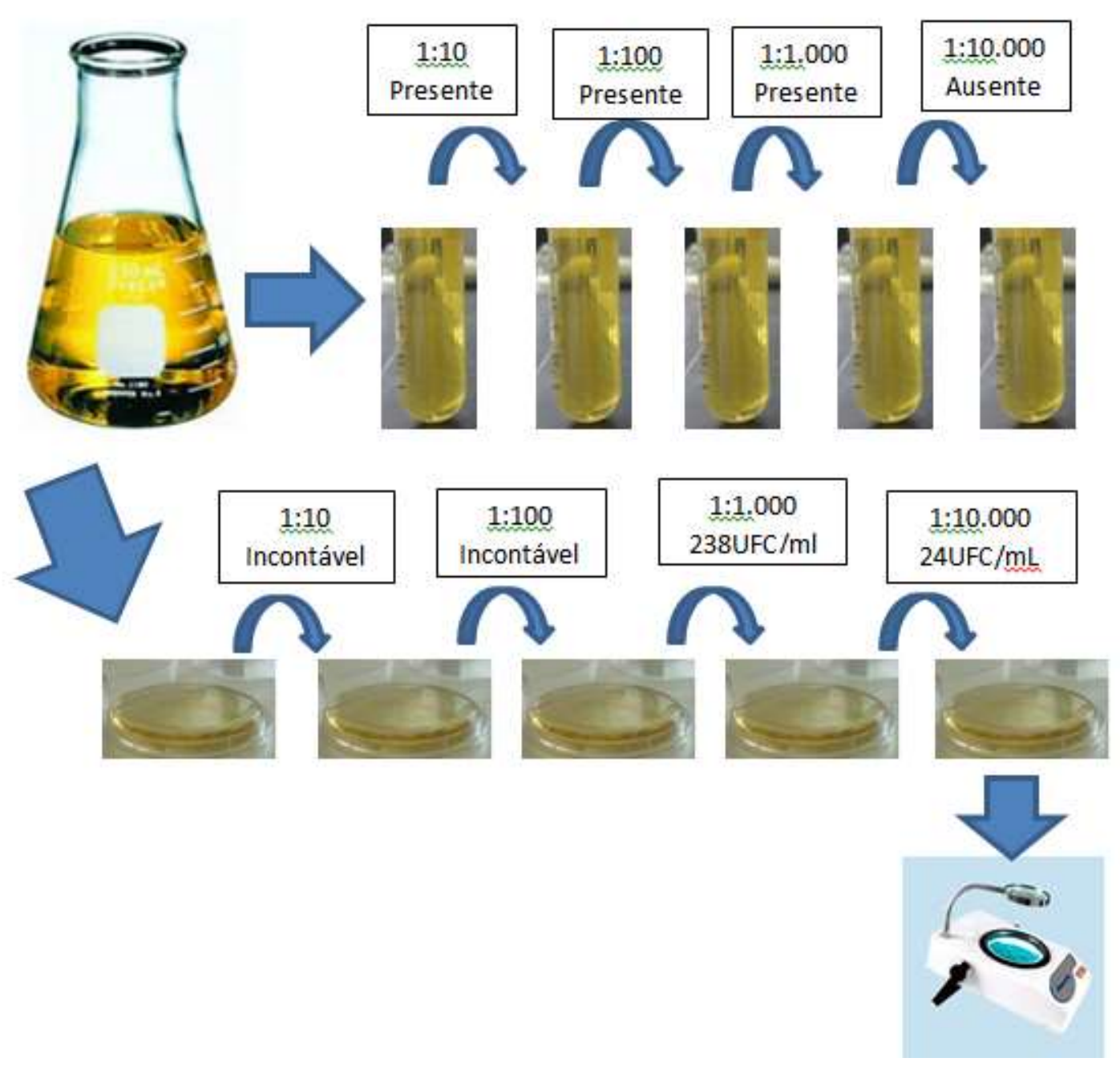

Figura 2. Esquema de diluições decimais para a realização do ensaio de limite de detecção. 

RESULTADOS E DISCUSSÃO 



\section{RESULTADOS E DISCUSSÃO}

\subsection{Análise por FTIR-ATR do crescimento microbiano}

Os espectros na região de 800 a $2000 \mathrm{~cm}^{-1}$ (primeira derivada suavizada) obtidos dos crescimentos de Bacillus subtilis (ATCC 6633), Candidaalbicans (ATCC 10231), Enterococcus faecium (ATCC 8459), Escherichia coli (ATCC 8739), Micrococcus luteus (ATCC 10240), Pseudomonas aeruginosa (ATCC 9027), Salmonella Typhimurium (ATCC 14028), Staphylococcus aureus (ATCC 6538) e Staphylococcus epidermidis (ATCC 12228) estão apresentados na Figura 3.

Os espectros forneceram informações quanto à composição de proteína, DNA/RNA, lipídios e carboidratos a partir do crescimento microbiano. Bandas intensas e amplas de amidas em torno de $1.660 \mathrm{~cm}^{-1}$ e $1.540 \mathrm{~cm}^{-1}$ foram obtidas devido à contribuição espectral das proteínas. Além disso, as bandas menos intensas fortemente sobrepostas de proteínas, DNA/RNA, lipídios e carboidratos podem ser visualizados na região entre 1.500 centímetros $^{-1}$ e $950 \mathrm{~cm}^{-1}$. Não pudemos deixar de notar que as diferenças nas constituições da parede celular microbiana foram evidenciadas na análise de espectros. Estas diferenças espectrais podem ser explicadas devido à presença de quantidades mais elevadas de peptidoglicano em bactérias GRAM -positivas e a presença de lipopolissacarídeos (LPS) em bactérias GRAM- negativas (Davis \& Mauer, 2010)(Helm \& Naumann, 1995). 


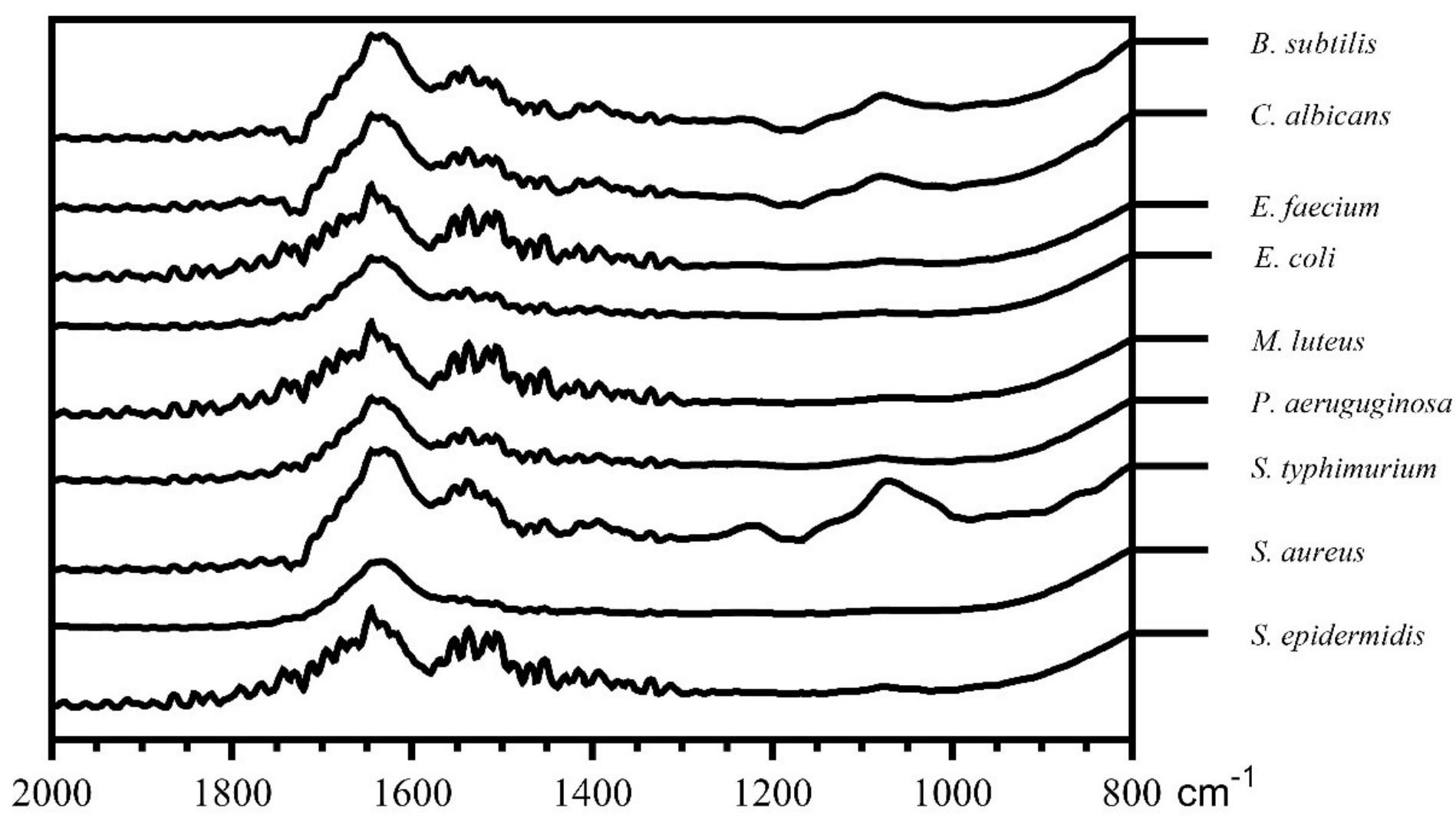

Figura 3. Espectros na região de 800 a $2000 \mathrm{~cm}^{-1}$ (primeira derivada suavizada) obtidos dos crescimentos de Bacillus subtilis (ATCC 6633), Candida albicans (ATCC 10231), Enterococcus faecium (ATCC 8459), Escherichia coli (ATCC 8739), Micrococcus luteus (ATCC 10240), Pseudomonas aeruginosa (ATCC 9027), Salmonella Typhimurium (ATCC 14028), Staphylococcus aureus (ATCC 6538) e Staphylococcus epidermidis (ATCC 12228). 
Visualmente, tem similaridade muito elevada e nenhum deslocamento significativo da faixa foram observados dos espectros de FTIR-ATR obtidos a partir do crescimento microbiana de Bacillus subtilis (ATCC 6633), Candid aalbicans (ATCC 10231), Enterococcus faecium (ATCC 8459), Escherichia coli (ATCC 8739), Micrococcusluteus (ATCC 10240), Pseudomonas aeruginosa (ATCC 9027), Salmonella Typhimurium (ATCC 14028), Staphylococcus aureus (ATCC 6538) e Staphylococcus epidermidis (ATCC 12228). No entanto, ligeiras alterações nas razões de absorbâncias podem ser visualizadas devido às diferenças qualitativas/ quantitativas da constituição de proteína, DNA/RNA, lipídios e carboidratos para os diferentes microrganismos (Kuligowski, et al., 2012).

\subsection{Exploração dos dados utilizando análise de componentes principais (PCA)}

Um modelo de análise de componentes principais (PCA) foi construído a partir dos 120 espectros (calibração) obtidos dos crescimentos de Bacillus subtilis (ATCC 6633), Candida albicans (ATCC 10231), Enterococcus faecium (ATCC 845), Escherichia coli (ATCC 8739), Micrococcus luteus (ATCC 10240), Pseudomonas aeruginosa (ATCC 9027), Salmonella Typhimurium (ATCC 14028,), Staphylococcus aureus (ATCC 6538) e Staphylococcus epidermidis (ATCC 12228), com $n=20$ de cada microrganismo. Um resumo dos resultados de PCA está apresentado na Tabela 3. 
Tabela 3.Resultados da análise de componentes principais (PCA) obtidos a partir dos espectros FTIR-ATR na região de 800 a $2000 \mathrm{~cm}-1$ (primeira derivada suavizada) dos crescimentos de Bacillus subtilis (ATCC 6633), Candida albicans (ATCC 10231), Enterococcus faecium (ATCC 8459), Escherichia coli (ATCC 8739), Micrococcus luteus (ATCC 10240), Pseudomonas aeruginosa (ATCC 9027), Sallmonella Typhimurium (ATCC 14028), Staphylococcus aureus (ATCC 6538) e Staphylococcus epidermidis (ATCC 12228).

\begin{tabular}{cccc}
\hline PC & Eigenvalues & Contribuição individual & Contribuição acumulada \\
\hline $\mathbf{1}$ & 379.11 & $60.9 \%$ & $60.9 \%$ \\
$\mathbf{2}$ & 145.63 & $23.4 \%$ & $84.4 \%$ \\
$\mathbf{3}$ & 66.80 & $10.7 \%$ & $95.1 \%$ \\
$\mathbf{4}$ & 19.34 & $3.1 \%$ & $98.2 \%$ \\
\hline
\end{tabular}

Os três primeiros componentes principais (PC1, PC2 e PC3) explicam juntos 95,1\% da variância e proporcionam uma boa separação de classes entre os espectros obtidos a partir do crescimento de Bacillus subtilis (ATCC 6633), Candida albicans (ATCC 10231), Enterococcus faecium (ATCC 8459), Escherichia coli (ATCC 8739), Micrococcus luteus (ATCC 10240), Pseudomonas aeruginosa (ATCC 9027), Salmonella Typhimurium (ATCC 14028), Staphylococcus aureus (ATCC 6538) e Staphylococcus epidermidis (ATCC 12228), conforme mostrado na Figura4. 


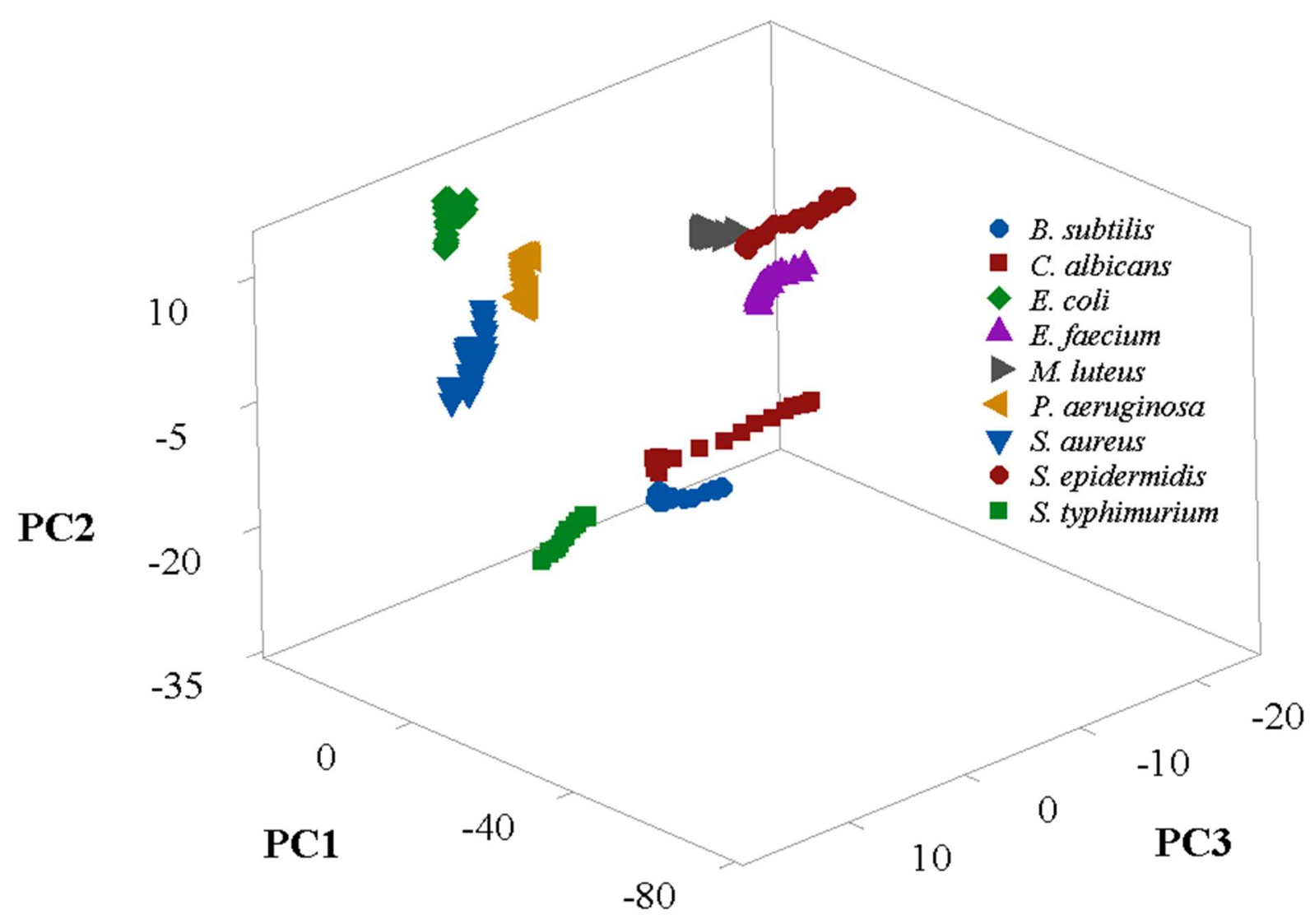

Figura 4.Gráfico de dispersão 3D dos scores para os 3 primeiros componentes principais (PC1, PC2 e PC3) para os espectros obtidos a partir do crescimento de Bacillus subtilis (ATCC 6633), Candida albicans (ATCC 10231), Enterococcus faecium (ATCC 8459), Escherichia coli (ATCC 8739), Micrococcus luteus (ATCC 10240), Pseudomona saeruginosa (ATCC 9027), Salmonella Typhimurium (ATCC 14028), Staphylococcus aureus (ATCC 6538) e Staphylococcus epidermidis (ATCC 12228). 
Apesar da boa separação da classe obtida, a PCA é frequentemente utilizada para explorar conjuntos de dados como método de classificação não supervisionado, bem como para detectar valores extensos. Assim, foi realizada uma análise de discriminante (LDA) a fim de construir um modelo de classificação com capacidade preditiva satisfatória.

\subsection{Classificação dos dados utilizando análise de discriminantes linear (LDA)}

O modelo de classificação foi obtido utilizando análise de discriminantes (LDA) a partir de quatro componentes principais preditores. O modelo LDA proporcionou uma boa separação de classe com o número razoável de preditores, o que foi confirmado por valores elevados de previsões corretas obtidos a partir de validação cruzada. Assim, este modelo de predição foi adotado para identificação rápida de contaminantes microbianos em produtos farmacêuticos. Uma síntese da matriz da confusão obtida com este modelo da predição foi mostrada na Tabela4. 
Tabela 4. Matriz de confusão obtida com o modelo LDA a partir dos espectros de FTIR-ATR na região entre 800 e $2000 \mathrm{~cm}-1$ (primeira derivada suavizada) com 4 PCs preditores.

\section{Microrganismos}

\begin{tabular}{|c|c|c|c|c|c|c|c|c|c|c|}
\hline $\begin{array}{c}\text { Classificação } \\
\text { obtida com } \\
\text { modelo } \\
\text { PCA/LDA }\end{array}$ & 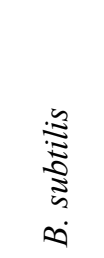 & 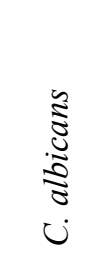 & 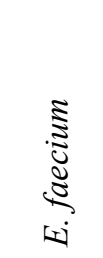 & $\begin{array}{l}\dot{0} \\
8\end{array}$ & 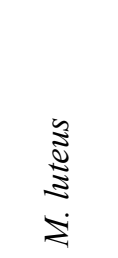 & 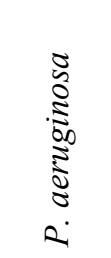 & 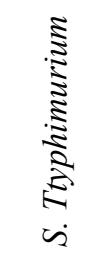 & 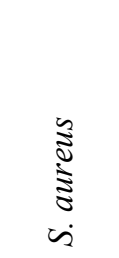 & 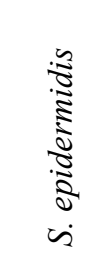 & $\frac{\substack{e \\
\frac{\pi}{0}}}{6}$ \\
\hline \multirow{3}{*}{ B. subtilis } & 20 & 0 & 0 & 0 & 0 & 0 & 0 & 0 & 0 & $100 \%$ \\
\hline & 20 & 0 & 0 & 0 & 0 & 0 & 0 & 0 & 0 & $100 \%$ \\
\hline & 10 & 0 & 0 & 0 & 0 & 0 & 0 & 0 & 0 & $100 \%$ \\
\hline \multirow{3}{*}{ C. albicans } & 0 & 20 & 0 & 0 & 0 & 0 & 0 & 0 & 0 & $100 \%$ \\
\hline & 0 & 20 & 0 & 0 & 0 & 0 & 0 & 0 & 0 & $100 \%$ \\
\hline & 0 & 10 & 0 & 0 & 0 & 0 & 0 & 0 & 0 & $100 \%$ \\
\hline \multirow{3}{*}{ E. faecium } & 0 & 0 & 20 & 0 & 0 & 0 & 0 & 0 & 0 & $100 \%$ \\
\hline & 0 & 0 & 20 & 0 & 0 & 0 & 0 & 0 & 0 & $100 \%$ \\
\hline & 0 & 0 & 9 & 0 & 0 & 0 & 0 & 0 & 0 & $100 \%$ \\
\hline \multirow{3}{*}{ E. coli } & 0 & 0 & 0 & 20 & 0 & 0 & 0 & 0 & 0 & $100 \%$ \\
\hline & 0 & 0 & 0 & 20 & 0 & 0 & 0 & 0 & 0 & $100 \%$ \\
\hline & 0 & 0 & 0 & 15 & 0 & 0 & 0 & 0 & 0 & $100 \%$ \\
\hline \multirow{3}{*}{ M. luteus } & 0 & 0 & 0 & 0 & 20 & 0 & 0 & 0 & 0 & $100 \%$ \\
\hline & 0 & 0 & 0 & 0 & 20 & 0 & 0 & 0 & 0 & $100 \%$ \\
\hline & 0 & 0 & 0 & 0 & 11 & 0 & 0 & 0 & 0 & $100 \%$ \\
\hline \multirow{3}{*}{ P. aeruginosa } & 0 & 0 & 0 & 0 & 0 & 20 & 0 & 0 & 0 & $100 \%$ \\
\hline & 0 & 0 & 0 & 0 & 0 & 20 & 0 & 0 & 0 & $100 \%$ \\
\hline & 0 & 0 & 0 & 0 & 0 & 13 & 0 & 0 & 0 & $100 \%$ \\
\hline \multirow{3}{*}{ S.Ttyphimurium } & 0 & 0 & 0 & 0 & 0 & 0 & 20 & 0 & 0 & $100 \%$ \\
\hline & 0 & 0 & 0 & 0 & 0 & 0 & 20 & 0 & 0 & $100 \%$ \\
\hline & 0 & 0 & 0 & 0 & 0 & 0 & 5 & 0 & 0 & $100 \%$ \\
\hline \multirow{3}{*}{ S. aureus } & 0 & 0 & 0 & 0 & 0 & 0 & 0 & 20 & 0 & $100 \%$ \\
\hline & 0 & 0 & 0 & 0 & 0 & 0 & 0 & 20 & 0 & $100 \%$ \\
\hline & 0 & 0 & 0 & 0 & 0 & 0 & 0 & 14 & 0 & $100 \%$ \\
\hline \multirow{3}{*}{ S. epidermidis } & 0 & 0 & 0 & 0 & 0 & 0 & 0 & 0 & 20 & $100 \%$ \\
\hline & 0 & 0 & 0 & 0 & 0 & 0 & 0 & 0 & 20 & $100 \%$ \\
\hline & 0 & 0 & 5 & 0 & 2 & 0 & 0 & 0 & 14 & $67 \%$ \\
\hline \multirow{3}{*}{ Total (\%) } & $100 \%$ & $100 \%$ & $100 \%$ & $100 \%$ & $100 \%$ & $100 \%$ & $100 \%$ & $100 \%$ & $100 \%$ & $100 \%$ \\
\hline & $100 \%$ & $100 \%$ & $100 \%$ & $100 \%$ & $100 \%$ & $100 \%$ & $100 \%$ & $100 \%$ & $100 \%$ & $100 \%$ \\
\hline & $100 \%$ & $100 \%$ & $64 \%$ & $100 \%$ & $85 \%$ & $100 \%$ & $100 \%$ & $100 \%$ & $100 \%$ & $94 \%$ \\
\hline
\end{tabular}

Classificação do modelo

Validação cruzada (Internal)

Validação externa 
Uma validação externa foi executada para desafiar o modelo de previsão. Crescimentos microbianos obtidos a partir de produtos farmacêuticos intencionalmente contaminados com Bacillus subtilis (ATCC 6633, $\mathrm{n}=10$ ), Candida albicans (ATCC 10231, n = 10), Enterococcus faecium (ATCC 8459, n = 14), Escherichia coli (ATCC 8739, $\mathrm{n}=15)$, Micrococcus luteus (ATCC 10240, $\mathrm{n}=13$ ), Pseudomonas aeruginosa (ATCC 9027, n = 13), Salmonella Typhimurium (ATCC 14028, n=5), Staphylococcus aureus (ATCC 6538, $\mathrm{n}=14$ ) e Staphylococcus epidermidis (ATCC 12228, $\mathrm{n}=14$ ) foram usados para validação externa. O modelo PCA/LDA com 4preditores forneceu predições corretas para 94\% (101 em 108) crescimentos microbianos obtidos a partir de produtos farmacêuticos intencionalmente contaminados.

Todas as classificações realizadas utilizando o modelo PCA/LDA com base no método FTIR-ATR estiveram de acordo com as identificações microbiológicas obtidas a partir de métodos microbiológicos tradicionais, utilizando ágar MacConkey, ágar cetrimide e ágar sal de manitol. Além disso, o método de FTIR-ATR forneceu identificação microbiana muito mais rápida quando comparado aos métodos tradicionais.

\subsection{Validação do método FTIR-ATR para identificação microbiana rápida}

O método FTIR-ATR para a identificação rápida de contaminantes microbianos em produtos farmacêuticos foi validado avaliando-se a sensibilidade e especificidade. Um resumo dos resultados de sensibilidade e especificidade está apresentado na Tabela 5. A sensibilidade encontrada foi de 93,5\%, o que indica uma boa capacidade de FTIR-ATR método para detectar a presença de microrganismos. Adicionalmente, a especificidade encontrada foi de $83,3 \%$. 
Tabela 5. Tabela de contingência para presença/ausência de crescimento microbiano e identificação microbiana rápida de contaminantes em produtos farmacêuticos pelo método FTIR-ATR.

\begin{tabular}{ccccc}
\hline $\begin{array}{c}\text { Método de } \\
\text { identificação } \\
\text { FTIR-ATR }\end{array}$ & \multicolumn{2}{c}{$\begin{array}{c}\text { Crescimento } \\
\text { microbiana }\end{array}$} & Total & Results \\
\cline { 2 - 3 } & Ausente & Presente & & \\
\cline { 1 - 3 } Negativo & 135 & 27 & 162 & Especificidade $=83,3 \%$ \\
Positivo & 7 & 101 & 108 & Sensibilidade $=93,5 \%$ \\
\hline
\end{tabular}

A ausência de microrganismos patogênicos em produtos farmacêuticos não estéreis é um requisito de qualidade (United States Pharmacopeia, 2016)(Agência Nacional de Vigilância Sanitária (ANVISA), 2010). Os produtos farmacêuticos para uso oral têm a exigência de ausência de Salmonela e Escherichia coli, embora os produtos tópicos exijam a ausência de Staphylococcus aureus e Pseudomonas aeruginosa. Apesar disso, outros microrganismos foram incluídos na validação, a fim de avaliar se o método FTIR-ATR pode distinguir entre microrganismos patogênicos e não patogênicos.

Além disso, o método FTIR-ATR para identificação microbiana rápida foi avaliado quanto ao limite de detecção. O limite de detecção encontrado esteve entre 17 e $23 \mathrm{UFC} / \mathrm{ml}$ de amostra para os microrganismos testados. 



\section{CONCLUSÕES}





\section{CONCLUSÕES}

- Foi desenvolvido e validado método de espectrometria no infravermelho com transformada de Fourier com reflectância total atenuada (FTIR-ATR) para a identificação rápida de contaminantes microbianos em produtos farmacêuticos.

- Análise de componentes principais (PCA) e análise de discriminante linear (LDA) foram utilizadas para obter um modelo preditivo capaz de distinguir entre o crescimento oriundos da contaminação por Bacillus subtilis (ATCC 6633), Candida albicans (ATCC 10231), Enterococcus faecium (ATCC 8459), Escherichia coli (ATCC 8739), Micrococcus luteus (ATCC 10240), Pseudomonas aeruginosa (ATCC 9027), Salmonella Typhimurium (ATCC 14028), Staphylococcus aureus (ATCC 6538) e Staphylococcus epidermidis (ATCC 12228).

- A identificação microbiana fornecida pelo modelo PCA/LDA com base no método FTIR-ATR foi compatível com aquelas obtidas empregando-se métodos microbiológicos tradicionais.

- Portanto, é notável que a espectroscopia FTIR-ATR pode ser usada para fornecer uma identificação rápida de contaminantes microbianos em produtos farmacêuticos. 

REFERÊNCIAS 



\section{REFERÊNCIAS}

Agência Nacional de Vigilância Sanitária (ANVISA), 2010. 5.5.3.1 Ensaios microbiológicos para produtos não estéreis. In:: Farmacopéia Brasileira. 5a ed. Brasília: s.n., pp. 233-250.

Alves, M. F. B., 2018. Ensaio de Eficácia de Conservantes. Lisboa: Faculdade de Ciências e Tecnologia - Universidade de Nova de Lisboa.

Amaral, F. D., 2016. Análise de riscos e pontos críticos de contaminação microbiana na manipulação de produtos e insumos farmacêuticos.. s.l.:Instituto de Ciência, Tecnologia e Qualidade Industrial (ICTQ).

Andrade, F. R. O., 2005. Análise Microbiologica de Materias Primas e Formulações Farmacêuticas Magistrais. Revista Eletrônica Farmácia, 2(2), pp. 38-44.

ANVISA, A. N. V. S. -., 2010. Boas Práticas de Fabricação de Medicamento. In:: RDC 17. s.1.:s.n.

Arrud, É. A. G. d., 1998. Infecção hospitalar por Pseudomonas aeruginosa multiresistente: análise epidemiológica no HC-FMUSP. Revista da Sociedade Brasileira de Medicina Tropica, set-out..pp. 503-504.

Arrud, É. A. G. d., 1998. Infecção hospitalar por Pseudomonas aeruginosa multiresistente: análise epidemiológica no HC-FMUSP. Revista da Sociedade Brasileira de Medicina Tropical, pp. 503-504. 
Baldini, R. L., 2010. Genes Envolvidos naPatogenicidade da Bactéria. [Online] Available at: $\quad$ http://www2.iq.usp.br/docente/baldini/ [Acesso em 15 SETEMBRO 2018].

Barban, D. B. A., 2010. Manual de Microbiologia Clínica para o Controle de Infecção Relacionada à Assistência à Saúde. Módulo 6 : Detecção e identificação de bactérias de importância médica. 1 ed. Brasilia: Agência Nacional de Vigilância Sanitári.

Barbosa, H. R., Gomez, J. G. C. \& Torres, B. B., 2018. Morfologia e Estruturas Bacterianas. In:: H. R. Barbosa, J. G. C. Gomez \& B. B. Torres, eds. Microbiologia Básica- Bactrtiologia. Rio Janeiro: Atheneu, pp. 34-35.

Bratfich, O. J., 2005. Epidermologia Molecualr de Staphylococcous epidermidis. São Paulo: s.n.

Bugno, A., Lira, R. S., Oliveira, W. A. \& Pinto, T. J., 2015. Application of Bact/Alert 3D system for sterility testing of injectable products. Brazilian Jouranl of Microbiology, Volume 46, pp. 73-747.

Bugno, A. et al., 2017. Performance Survey and Comparison Between Rapid Sterility Testing Method and Pharmacopeia Sterility test. Journal of Pharmaceutical Innovation, 05 December, pp. s12247-017-9303-z.

Corrêa, G. d. O. P., 2018. Avaliação in vitro da citotoxicidade e potencial de irritação de conservante antimicrobianos utilizados em cosméticos. Araraquara, São Paulo: Universidade Estadual Paulista "Julio de Mesquita Filho". 
Davis, R. \& Mauer, L. J., 2010. Fouriet transform infrared (FT-IR) spectroscopy: a rapid tool for detection and analysis of foodborne pathogenic bacteria. In:: Current Research, Technology and Education Topics in Applied Microbiology and Microbial Biotechnology. s.1.:s.n., pp. 1582-1594.

Denyer, S. P. \& Baird, R. M., 2007. Guide to microbiological control in pharmaceuticals and medical devices. 2nd ed. New York: Taylor \& Francis Group.

Easter, M. E., 2003. Rapid microbiological methods in the pharmaceutical industry. Florida: CRC Press.

Ferreira, J. A., 2017. Deteção e identificação rápidas dos principais contaminantes microbiológicos em fármacos por espetroscopia de infravermelho. Lisboa: s.n.

Ferreira, L. L., 2005. Estrutura clonal e multirresistência em Pseudomonas aeruginosa. Rio Janeiro: INCQS/ FIOCRUZ.

Ferreira, M. R. et al., 2014. An innovative challenge test for solid cosmetics using freezedried microorganisms and electrical methods. Journal of Microbiological Methods, Volume 106, pp. 104-109.

Filip, Z., Herrmann, S. \& Kubat, J., 2004. FT-IR spectroscopic characteristics of differently cultivated Bacillus subtilis. Microbiological Research, Volume 159, pp. 257262. 
Fischer, G., Braun, S., Thissen, R. \& Dott, W., 2006. FT-IR spectroscopy as a tool for rapid identification and intra-species characterization of airborne filamentous fungi. Journal of Microbiological Methods, Volume 64, pp. 63-77.

Franzolin, M. R., 2004. Indentificação Bioquimica: Fundamentos. In:: M. R. Franzolin, ed. Microbiologia. São Paulo: Atheneu, pp. 683- 697.

Fung, D. Y., 2002. Rapid Method and Automation in Microbiology. Comprehensive Reviews in Food Science Safety, Volume 1, pp. 3-22.

Garcia, S. R. P. \& Neto, A. C., 2015. Modelo de Regressão por minimos quadrados parciais para dados de monitoramento de barragens. Engenho, Volume 11, pp. 1-20.

Helm, D. \& Naumann, D., 1995. Identification of some bacteria cell components by FTIR spectroscopy. FEMS Microbiology Letters, Volume 126, pp. 75-80.

Hongyu, K., Sandanielo, V. L. M. \& Junior, G. J. d. O., 2015. Análise de Componentes Principais: resumo teórico, aplicação e interpretação. Engineering and Science, 1(5), pp. $1-8$

Kane, S. R. et al., 2009. Rapid, high-throughput, culture-based PCR methods to analyze samples for viable spores of Bacillus anthracis and its surrogates. Journal of Microbiological Methods, Volume 76, pp. 278-284.

Kuligowski, J., Quintás, G., Herwig, C. \& Lendl, B., 2012. A rapid method for the differentiation of yeast cells grown under carbon and nitrogen-limited conditions by 
means of partial least squares discriminant analysis employing infrared microspectroscopic data of entire yeast cells. Talanta, Volume 99, pp. 566-573.

Leme, L. B., 2013. Características de adesão de cepas de Escherichia coli isoladas de pacientes com Doença Inflamatória Intestinal. pp. 1-33.

Liu, X. et al., 2016. Development of a highly sensitive laterial immunochromatographic assay for rapid detection of Vibrio parahaemolyticus. Journal of Microbiological Methods, Volume 131, pp. 78-84.

Lourenço, F. R. et al., 2015. Design space approach for preservative system optimization of an anti-aging eye fluid emulsion. Journal of Pharmacy \& Pharmaceutical Sciences, Volume 18, pp. 551-561.

Martins, L. M., 2010. Estudo de Salmonella Typhimurium de origem aviaria: perfil genotipico, colonização e invasãoLidi. São Paulo: s.n.

Maurischat, S., Szabo, I., Baumann, B. \& Malorny, B., 2015. Rapid real-time PCR methods to distinguish Salmonella Enteriridis wildtype field isolates from vaccine strains Salmovac SE/Gallivac SE and AviPro SALMONELLA VAC E. Journal of Microbiological Methods, Volume 112, pp. 92-98.

Moretto, L. D. \& Calixto, J., 2009. Estrutura de novo sistema da qualidade para a indústria farmacêutica. In:: cap.1. 5a ed. s.1.:Sundusfarma, pp. 3-11.

Mota, V. A. M., 2017. O controle da contaminação microbiológica de produtos magistrais. Revista Brasleira Multidiciplinares, 20(1), pp. 33-49. 
Naumann, D., 2000. Infrared Spectroscopy in Microbiology. pp. 102-131.

Pacheco, F. L. \& Pinto, T. J., 2010. The bacterial diversity of pharmaceutical clean rooms analyzed by the fatty acid methyl ester technique. PDA Jouranl of Pharmaceutical Science And Technology, Volume 64, pp. 156-166.

Paiva, A. P. d., 2006. Metodologia Superficie de Respostas e Análise de Componentes Principais em Otimização de Processo de Manufatura com Multiplas Resposatas Correlaciondas. Itajubá: s.n.

Paiva, D. L., 2010. Introdução á espectroscopia. 4 ed. São Paulo: Cengage.

Parveen, S. et al., 2011. Evaluation of growth based rapid microbiological methods for sterility testing of vaccines and other biological products. Vaccine, Volume 29, pp. 80128023

Pinto, T. d. J. A., Kaneko, T. M. \& Pinto, A. F., 2015. Contaminação microbiana em produtos farmacêuticos, correlatos e cosméticos. In:: Controle Biológico de Qualidade de Produtos Farmacêuticos, Correlatos e Cosméticos. 4ª ed. São Paulo: Manole, pp. 5875.

Pinto, T. d. J. A., Kaneko, T. M. \& Pinto, A. F., 2015. Métodos alternativos para enumeração e identificação de microrganismos. In:: Controle Biológico de Qualidade de Produtos Farmacêuticos, Correlatios e Cosméticos. 4a ed. São Paulo: Manole, pp. 129151. 
Pinto, T. d. s. A., Kaneko, T. M. \& Pinto., A. F., 2015. Eficácia Conservante. In:: Controle Biológico de Qualidade de Produstos Farmacêuticos, Correlatos e Cosméticos. Barueri, São Paulo: Manole, pp. 303-330.

Pinto, T. J. A., Kaneko, T. M. \& Pinto, A. F., 2014. Controle biológico de qualidade de produtos farmacêuticos, correlatos e cosméticos. $4^{\mathrm{a}}$ ed. São Paulo: Manole.

Popp, M. M. d. S. e. R. J., 1999. Avaliação de uso de métodos quimiometricos em análise de solos. Campinas: s.n.

Shah, N. \& Naseby, D. C., 2015. Validation of constitutively expressed bioluminescent pseudomonas aeruginosa as a rapid microbiological quantification tool. Biosensors and Bioelectronics, Volume 68, pp. 447-453.

Siuza, D. S., 2010. Produtos Fitoterápicos e a Necessidade de um controle de qualidade microbiologico. VEREDAS FAVIP - Revista Eletrônica de Ciências , 3(2), pp. 1-9.

SKOOG, D. A., 2002. Análise Instrumental. 5 ed. Porto Alegre: Bookman.

Song, C., Li, J., Liu, J. \& Liu, Q., 2016. Simple sensitive rapid detection of Escherichia coli $\mathrm{O} 157: \mathrm{H} 7$ in food samples by label-free immunofluorescence strip sensor. Talanta, Volume 156-157, pp. 42-47.

Souza, V. S. d., 2017. Avaliação do sistema conservante frente á ação microbiologica em preparação farmaceutica. Rio de Janeiro: Fiocruz. 
Taguri, T. et al., 2011. A rapid detection method using flow cytometry to monitor the risk of Legionella in bath water. Journal of Microbiological Methods, Volume 86, pp. 25-32.

Theisen, J., 2010. Suscetibilidade de Staphylococcous epidemidis Á vancomicina, rifampicina, azitromicina e eritromicina. Porto Alegre: s.n.

Tidwell, J. E. et al., 2015. Can near-infrared spectroscopy detect and differentiate implant-associated biofilms?. Clinial Orthopaedics and Related Research, Volume 473, pp. 3638-3646.

Tong, M.-Y., Jiang, C. \& Armstrong, D. W., 2010. Fast detection of Candida albicans and/or bacteria in blood plasma by "sample-self-focusing" using capillary electrophoresis-laser-induced fluorescence. Journal of Pharmaceutical and Biomedical Analysis, Volume 53, pp. 75-80.

Ugarova, N. N. et al., 2016. A simplified ATP method for the rapid control of cell viability in a freeze-dried BCG vaccine. Journal of Microbiological Methods, Volume 130, pp. $48-53$.

United States Pharmacopeia, 2016. $<1112>$ Application of water activity determination to nonsterile pharmaceutical products. In:: Rockville: United States Pharmacopeial Convention.

United States Pharmacopeia, 2016. $<1223>$ Validation of alternative microbiological methods. In:: Rockville: United States Pharmacopeial Convention. 
United States Pharmacopeia, 2016. <61> Microbiological examintation of nonsterile products: microbial enumeration tests. In:: Rockville: United States Pharmacopeial Convention.

United States Pharmacopeia, 2016. $<62>$ Microbiological examination of nonsterile products: tests for specified microorganisms. In:: Rockville: United States Pharmacopeial Convention.

Varella, C. A. A., 2010. Análise Multivariada Aplicada á Ciencias Agrárias. Rio de Janeiro: s.n.

Verdonk, G. P. et al., 2010. The most probable limit of detection (MPL) for rapid microbiological methods. Journal of Microbiological Methods, Volume 82, pp. 193-197.

Wu, S.-M., Chen, J., Ai, X.-X. \& Yan, Z.-Y., 2013. Detection of Escherichia coli in drugs with antibody conjugated quantun dots as immunofluorescence probes. Journal of Pharmaceutical and Biomedical Analysis, Volume 78, pp. 9-13. 